\title{
A contact-area model for rail-pads connections in 2-D simulations: sensitivity analysis of train induced vibrations
}

\author{
R. Ferrara*†‡, G. Leonardi $†$ and F. Jourdan $\ddagger$ \\ $\dagger$ DICEAM, University of Reggio Calabria, Italy \\ $\ddagger$ LMGC, University Montpellier 2, France
}

Vehicle System Dynamics: International Journal of Vehicle Mechanics and Mobility published online: 11 Jun 2013

\begin{abstract}
A numerical model to predict train induced vibrations is presented. The dynamic computation considers mutual interactions in vehicle/track coupled systems by means of a finite and discrete elements method. The rail defects and the case of out-of-round wheels are considered. The dynamic interaction between the wheel-sets and the rail is accomplished by using the non-linear Hertzian model with hysteresis damping. A sensitivity analysis is done to evaluate the variables affecting more the maintenance costs. The rail-sleeper contact is assumed extended to an area defined contact-zone, rather than a single point assumption which fits better real case studies. Experimental validations show how prediction fits well experimental data.
\end{abstract}

\section{Introduction}

The main causes of vibrations induced by train traffic are: rail irregularity, wheel defects and variation of stiffness due to discrete supporting of rail. Effects of vibrations influence the maintenance of track (ballast principally), passenger comfort and the wave propagation in the environment. Predicting vibrations, displacements, accelerations and contact-forces is not an easy and immediate process. This is mainly due to the number of parameters, the behavior of different elements, the heterogeneity of track properties and corrugation.

Numerous studies have been conducted to simplify this problem. Some works $[1,2,3]$ studied the wave propagation through the track-ground system in three dimensions, modeling contact forces as constant or harmonic vertical forces moving along the rails. Others $[4,5,6,7,8]$ studied the coupled train/track system in two dimensions; they modeled rail as an Euler-Bernoulli or a Timoshenko beam connected to pads by singular points. $[9,10]$ studied the vehicle/track coupled system modeling with finite elements the rail, considering it connected to pads by singular points and discretizing the rail with a singular finite element for each pair of sleepers. Furthermore, they discretized the rail with a singular finite element for each pair of sleepers. Actually, the rail/sleepers contact zone is not negligible if compared to the length of the rail suspended between two consecutive sleepers. In fact, sleeper base measures between 60 and $70 \mathrm{~cm}$ and the pad length measures between 17 and $26 \mathrm{~cm}$. In addition, the midspan point of the rail assumes the maximum displacement during vibration, that cannot be modeled with a singular element between two sleepers. Finally, the shear effects for rail finite elements are neglected in $[9,10]$ that is not acceptable because the classical hypothesis for slender beams is not applicable in this case. In fact, the height of rail section is $14.8 \mathrm{~cm}$ for a $50 U N I$ rail and $17.2 \mathrm{~cm}$ for a $60 U N I$ rail [11], that is not small enough if compared to the length of a beam element.

\footnotetext{
*Corresponding author. Email: riccardo85ferrara@gmail.com
} 
In this work the vehicle is modeled as seven discrete elements in accordance to [5, 12, 10, 13], rail is modeled as finite elements considering shear effect and the algorithm allows to choose the number of elements between two sleepers. Moreover, it is possible to create different meshes for elements connected to pads and for suspended elements. As the variation of track stiffness met by wheels during motion is one of the causes of vibrations, precision of connections has been increased introducing a series of spring/damper elements placed along all the longitudinal length of the sleeper [14]. As explained further in this paper, we implemented a particular algorithm for the resolution of the motion equations, that allows the reduction of computational time. More in detail, the algorithm solves the non-linear contact problem combining a fixed point and a Newton-Raphson method. The problem is studied in two dimensions, assuming flat railway, absence of bends and neglecting the rolling motion of the vehicle. The work presented allows to extend the analysis to different types of wagon. The case studies are related to a locomotive, i.e. the heavier wagon of a passenger trains and the one producing the worst effects. However freight vehicles may be heavier; simple variations of the vehicle model parameters may be carried out to evaluate further case studies.

\section{Description of the model}

\subsection{The vehicle model}

The vehicle is modeled by seven two-dimensional rigid elements corresponding to the body, two bogies and four wheels. It is assumed that the problem is symmetric, so masses are considered half of their actual values. Bogies are suspended on wheels by primary suspensions represented by a spring-damper couple. Similarly, the vehicle body is linked with bogies by secondary suspensions. Ten degrees of freedom are considered: the vertical displacement of vehicle body, bogies and wheels; the pitch of bogies and vehicle body. All mechanical parameters and the degrees of freedom are represented in Figure 1. The equation of motion in matrix form is

$$
\mathbf{M}_{v} \ddot{\mathbf{z}}_{v}+\mathbf{C}_{v} \dot{\mathbf{z}}_{v}+\mathbf{K}_{v} \mathbf{z}_{v}=\mathbf{q}_{v}-\mathbf{f}_{v}
$$

where $\mathbf{M}_{v}, \mathbf{K}_{v}$ and $\mathbf{C}_{v}$ are stiffness, damping and mass matrix of the vehicle, as defined in appendix; $\mathbf{z}_{v}$ is the assembled vector of the ten degrees of freedom; $\mathbf{q}_{v}$ is the forces vector which contains the gravitational forces and $\mathbf{f}_{v}$ contains the wheel-rail contact forces.

\subsection{The wheel-rail contact}

The problem of contact between wheel and rail has been studied in details by $[15,16,17,18,19]$. In our model, contact forces between the $j^{\text {th }}$ wheel and rail are computed by the non-linear Hertz's model with hysteresis damping as defined by Lankarani and Nikravesh $[18,19]$ as

$$
R_{w / r, j}= \begin{cases}K_{h} \delta^{\frac{3}{2}}+C_{h} \dot{\delta} & \text { if } \delta>0, \\ 0 & \text { if } \delta<0 ;\end{cases}
$$

where $\delta$ is the total deflection of wheel and rail at the contact point computed as

$$
\delta=z_{w j}-z_{r j}-\eta_{r j},
$$

in which $z_{w j}$ is the vertical displacement of the $j^{t h}$-wheel, $z_{r j}$ and $\eta_{r j}$ are the displacement and the vertical defect of rail at $j^{t h}$-contact-point respectively; $K_{h}$ and $C_{h}$ are the Hertzian and the damping contact coefficient. During the phase of calibration of the model the non dissipative behavior of the Hertz's contact emerged. So at the end of calibration the damping coefficient $C_{h}$ is neglectable. 


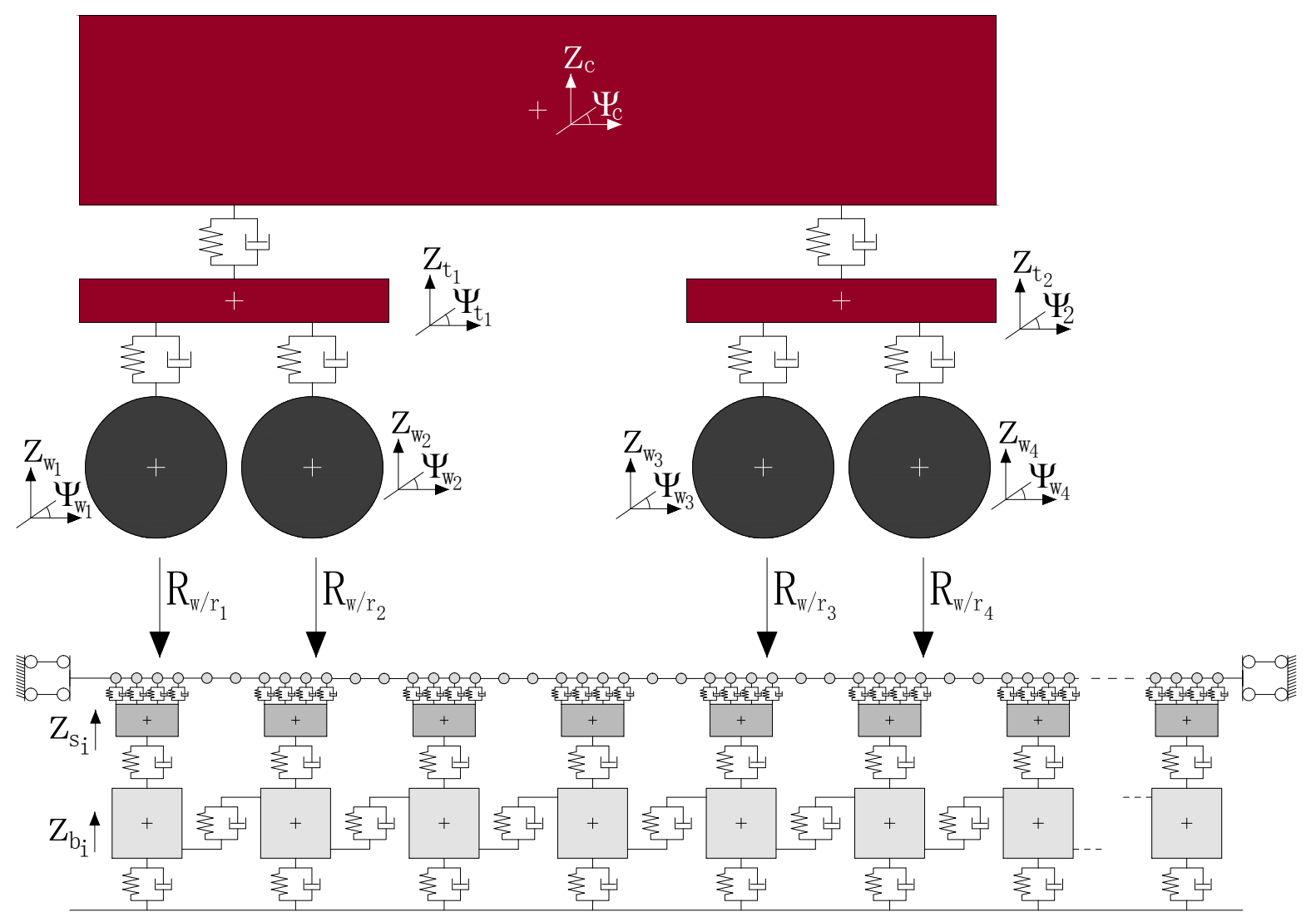

Figure 1: Draft of the model. 


\subsection{The rail model}

A finite element discretization is used to model the rail. Considering insignificant the axial displacement, we discretized the rail with Timoshenko beam finite elements with two degrees of freedom: rotation and vertical displacement. The algorithm allows to choose the number of beam elements between two sleepers and the number of beam elements vertically connected to sleeper by pads. Similarly to the Eq. (1), motion equation for rail may be expressed as

$$
\mathbf{M}_{r} \ddot{\mathbf{z}}_{r}+\mathbf{C}_{r} \dot{\mathbf{z}}_{r}+\mathbf{K}_{r} \mathbf{z}_{r}=\mathbf{q}_{r}+\mathbf{f}_{r},
$$

where $\mathbf{z}_{r}$ is the nodal displacement-rotation vector of $2 n$-dimensions if $n$ is the total number of nodes; $\mathbf{M}_{r}$ is the lumped mass matrix written also considering the inertial effects associated to rotational degrees of freedom, $\mathbf{K}_{r}$ and $\mathbf{C}_{r}$ are the stiffness and the damping matrix respectively, $\mathbf{q}_{r}$ is the forces vector which contains the gravitational forces and $\mathbf{f}_{r}$ contains the wheel-rail contact forces.

\subsection{Description of rail-pads, sleepers and ballast model}

In comparing mass and stiffness between rail-pads and concrete sleepers, rail-pad mass $(1 \sim 2 \mathrm{~kg})$ is negligible if compared to concrete sleeper mass $(250 \sim 350 \mathrm{~kg})$; similarly, sleeper stiffness $\left(K_{s}=30 \sim\right.$ $\left.40 \cdot 10^{12} \mathrm{~N} \mathrm{~m}^{-1}\right)$ is six orders of magnitude higher than pad stiffness $\left(15 \sim 25 \cdot 10^{6} \mathrm{~N} \mathrm{~m}^{-1}\right)$. Moreover, rail-pads should not be modeled as a punctual connection like $[5,9,13,7,20]$, because rail-pads length cannot be neglected if compared to sleeper base. Therefore, rail-pad is modeled as a combination of spring-damper couples without mass. In accordance with [12, 13, 5, 20,9] the sleeper is modeled as a discrete rigid element and the ballast is modeled as single blocks placed in correspondence of sleepers. A spring-damper couple, representing the elasticity and viscosity of the ballast blocks, connects them with sleeper-elements. Other spring-damper couples connect ballast blocks horizontally, allowing the transmission of vibration along the motion direction. Ballast stiffness is calculated according to [21], so the stiffness for a ballast block is:

$$
k_{b}=\frac{2 \tan \varphi\left(l_{s}-b_{s}\right) E_{b}}{\ln \left[\frac{l_{s}\left(2 \tan \varphi h_{b}+b_{s}\right)}{b_{s}\left(2 \tan \varphi h_{b}+l_{s}\right)}\right]},
$$

in which $\varphi$ is the internal friction angle of ballast, $l_{s}$ and $b_{s}$ are the dimensions of the effective contact area between ballast and sleepers, $h_{b}$ and $E_{b}$ are the height and the modulus of elasticity of the ballast respectively. In accordance with [5] coefficients for longitudinal springs and dampers are calculated as $30 \%$ of the respective vertical coefficient. To represent the behavior of background, a spring-damper couple is added over ballast blocks (see Figure 1). The motion equations for the substructure are:

$$
\mathbf{M}_{s u b} \ddot{\mathbf{z}}_{s u b}+\mathbf{C}_{\text {sub }} \dot{\mathbf{z}}_{s u b}+\mathbf{K}_{\text {sub }} \mathbf{z}_{s u b}=\mathbf{q}_{\text {sub }}+\mathbf{f}_{\text {sub }} .
$$

The sub-matrices and the assembling procedure are described in Appendix B.

\subsection{Numerical model of wheel and rail defects}

Two models have been used to generate track irregularities. The first one is suggested by the ISO3095 [22], the International Organization for Standardization that reports the frequency spectrum of rail irregularities. The roughness profile has been evaluated in $1 / 3$ octave bands discretizing each band with 50 wavelengths. The procedure to generate the roughness profile is described in [23]. The second model, used by Association of American Railway (AAR) [9], allows to simulate the oldness of track varying the grade of irregularities.

\section{Resolution of dynamic equations}

In order to solve the non linear system of equations (1), (6), displacements and speeds are written as function of accelerations applying the linear acceleration method (Newmark scheme with $\delta=1 / 2$ and 
$\theta=1 / 6)$. Therefore the equation system of vehicle and substructure may be rewritten in the following discrete form:

$$
\begin{gathered}
\mathbf{F}_{v}\left(\ddot{\mathbf{z}}_{v, i+1}\right)=\mathbf{A}_{v} \ddot{\mathbf{z}}_{v, i+1}+\mathbf{f}_{v, i+1}\left(\ddot{\mathbf{z}}_{v, i+1}, \ddot{\mathbf{z}}_{s u b, i+1}\right)-\mathbf{b}_{v, i}=\mathbf{0} \\
\mathbf{F}_{s u b}\left(\ddot{\mathbf{z}}_{s u b, i+1}\right)=\mathbf{A}_{s u b} \ddot{\mathbf{z}}_{s u b, i+1}+\mathbf{f}_{s u b, i+1}\left(\ddot{\mathbf{z}}_{v, i+1}, \ddot{\mathbf{z}}_{s u b, i+1}\right)-\mathbf{b}_{s u b, i}=\mathbf{0}
\end{gathered}
$$

where

$$
\begin{gathered}
\mathbf{A}_{\alpha}=\left(\mathbf{M}_{\alpha}+\frac{\Delta t}{2} \mathbf{C}_{\alpha}+\frac{\Delta t^{2}}{6} \mathbf{K}_{\alpha}\right), \\
\mathbf{b}_{\alpha, i}=\left[\mathbf{q}_{\alpha}-\mathbf{C}_{\alpha}\left(\dot{\mathbf{z}}_{\alpha, i}+\frac{\Delta t}{2} \ddot{\mathbf{z}}_{\alpha, i}\right)-\mathbf{K}_{\alpha}\left(\mathbf{z}_{\alpha, i}+\Delta t \dot{\mathbf{z}}_{\alpha, i}+\frac{\Delta t^{2}}{3} \ddot{\mathbf{z}}_{\alpha, i}\right)\right],
\end{gathered}
$$

for $\alpha=v$ or $s u b$. These two systems of equations are coupled by the forces vector. In fact, the contact forces $R_{r / w}$ are inside both vectors $\mathbf{f}_{v, i+1}$ and $\mathbf{f}_{s u b, i+1}$ with opposite signs. The forces vector is a non linear function of accelerations in both equations, that would allow to solve the non linear system with the fixed-point iterative method like [9] or with the Newton-Raphson iterative method. Nevertheless, to reduce computational time and maintain accuracy, a different procedure that mixes both methods is proposed.

At the first fixed-point iteration of each time-step, substructure equations are solved with the implicit integration method. At this iteration, contact forces may be calculated with Eq. (2); $R_{w / r}$ is calculated as function of vehicle and substructure displacements relative to previous time-step; differently, rail defect values are associated to current time-step. The now calculated displacement vector of the substructure becomes input for the the Newton-Raphson method applied to the vehicle dynamic equation. Afterwards, the non-linear contact force is calculated for every Newton-Raphson iteration as function of vehicle displacements (that varies for every N.R. ${ }^{1}$ iteration); substructure displacements are temporally assumed as constant.

The Jacobian associated to the vehicle system (7a) is:

$$
\mathbf{J}=\mathbf{A}_{v}+\left[\begin{array}{cc}
\mathbf{0}_{6 \times 6} & \mathbf{0}_{6 \times 4} \\
\mathbf{0}_{4 \times 6} & \frac{\partial \mathbf{r}}{\partial \ddot{\mathbf{z}}_{w}} \\
\end{array}\right],
$$

where $\frac{\partial \mathbf{r}}{\partial \mathbf{z}_{w}} 4 \times 4$ is a diagonal matrix and diagonal elements are defined as:

$$
\delta r_{j j}=C_{h} \frac{\Delta t^{2}}{4}\left[z_{i_{w, j}}+\Delta t \dot{z}_{i_{w, j}}+\frac{\Delta t^{2}}{6}\left(\ddot{z}_{i+1_{w, j}}+2 \ddot{z}_{i_{w, j}}\right)-z_{i_{r, j}}-\eta_{i_{r, j}}\right]^{\frac{1}{2}} .
$$

Once the Jacobian is defined, the solution $\ddot{\mathbf{z}}_{i+1}$ may be calculated as limit of the sequence $\left[\ddot{\mathbf{z}}_{i+1}^{k}\right]_{k \in \mathbb{N}}$, where the apex $k$ is relative to the $k^{t h}$ N.R. iteration, as follows ${ }^{2}$ :

$$
\mathbf{J}\left(\ddot{\mathbf{z}}_{i+1}^{k}\right)\left(\ddot{\mathbf{z}}_{i+1}^{k+1}-\ddot{\mathbf{z}}_{i+1}^{k}\right)=-\mathbf{F}\left(\ddot{\mathbf{z}}_{i+1}^{k}\right),
$$

At the end of N.R. iterations a new contact-force vector and a new displacement vector are calculated for the vehicle. Then, the new contact-forces become input for the next f.p. ${ }^{3}$ iteration. At each f.p. iteration, convergence is checked on the displacement vector of the substructure, as:

$$
\frac{\operatorname{norm}\left(\mathbf{z}_{s_{j}}-\mathbf{z}_{s_{j-1}}\right)}{\operatorname{norm}\left(\mathbf{z}_{s_{j}}\right)} \leq \epsilon,
$$

where $\epsilon$ is the tolerance and subscript represents the $j^{t h}$ f.p. iteration. If the inequality (12) if satisfied, the algorithm goes to the next time step. Similarly, convergence is checked on displacement vector of the vehicle to proceed with the N.R. iterations.

\footnotetext{
${ }^{1}$ Newton-Raphson.

${ }^{2}$ subscript " $\mathrm{v}$ " is omitted to simplify notations

3 fixed-point.
} 
The strength of this algorithm consists in treating the non linearity of contact forces for every f.p. iteration applying N.R. only to the vehicle system. In fact, the dimensions of the vehicle matrices are widely lower than the substructure ones, so the factorization and the vehicle system resolution result faster. Moreover, treating a part the non linearity of the vehicle system allows a reduction of f.p. iterations. A global overview of the method is presented in Figure 2. The algorithm has been programmed with the software MATLAB.

\section{The importance of the contact-area model for the receptance analysis}

A draft of the difference between the contact-area and the contact-point models is shown in Figure 3. It is clear how the deformed shapes could be very different in the two cases. The importance of the contact-area model related to the receptance estimation of the railway track is shown in the Figure 4 and Figure 5. The contact-point model produces errors especially in the range of the pinned-pinned frequency. In this frequency range, it overestimates the receptance by $400 \%$ in the case of midspan excitation. Additionally, in the case of on-sleeper excitation, the receptance is underestimated by $150 \%$. On the contrary, the contact-area model fits closely the experimental data that could be explained by the analogy with a simply supported beam. In this case, the amplitude of deflection associated with the fundamental frequency is proportional to the length. Similarly, in the contact-area model the length of the rail not supported by pads is shorter than the one of the contact-point model; consequently also the receptance is lower. All the parameters used in the simulation are reported in Table 3.

\section{Validation of the numerical model}

A comparison with experimental results and other numerical models is carried out to validate the present model. To have a correct approximation and avoid an excessive extension of the computational time, an appropriate number of finite elements is chosen. The part of rail between two consecutive sleepers is discretized as nine beam elements while the the one vertically connected to sleepers by pads with six beam elements. The model is applied to a set of railway lines with different properties.

\subsection{Case 1 - corrugated rail (AAR [9]) - comparison with experimental results}

The first railway section, $64.35 \mathrm{~m}$ long, is relative to the Italian line Alcamo-Marsala $(116 \mathrm{~km})$, an old line with wooden sleepers. In this railway, measurements have been carried out with a series of accelerometers by [13]. A $A L n 688$ train with a single configuration, having a velocity of $90 \mathrm{~km} \mathrm{~h}^{-1}$, has been considered. The model parameters are shown in Table 1. A comparison between experimental data [13] and numerical results of the rail vertical acceleration is shown in Figure 6; a comparison between sleeper vertical acceleration is shown in Figure 7. Experimental data (Figure 6(a)) show how the rail vertical acceleration peaks are included between $50 \mathrm{~m} \mathrm{~s}^{-2}$ and $100 \mathrm{~m} \mathrm{~s}^{-2}$ and occur in correspondence of the four wheel-set passages. This behavior is predicted by the numerical simulation as well (Figure 6(b)). Additional experimental data (Figure 7(a)) shows how peaks of sleeper vertical acceleration occur in correspondence of bogie passage but they are not distinguishable for each wheel-set. Figure 7(b) shows how the present model predicts well this kind of behavior. The irregularity grade of railway is unknown so it has to be assumed. To study the influence of uncertainties connected to line grade index, many simulations have been implemented. Numerical results and experimental data have been compared in function of the line grade index. The worst value of index $\left(I_{l g}=1\right)$ allows numerical simulation to fit well experimental data. Furthermore, this case is referred to an old line so it is supposable that defects are relevant. 


\subsection{Case 2: out-of-round wheels - comparison with experimental results and other nu- merical models}

The second railway line model has been developed on the basis of the field testing results reported by [25]. Their study has been carried out to analyze vertical interaction between wagon and track in case of out-of-round wheels. Wheels have been artificially ground with a defect $40 \mathrm{~mm}$ long and $0.35 \mathrm{~mm}$ deep. Experimental data has been used by [5] to validate the model. The discretization adopted for the rail is the same of the precedent case. Because of the few parameters reported by [25], model parameters for train and substructure have been extracted both from [5] and [25]. All values are reported in Table 2. A comparison between experimental data [5] and numerical results for the second railway line is shown in Figure 8. A simulation with no rail defects have been developed by other authors too [5, 25] (see Figure 9(a) and 9(b)). Focusing on Figure 8(a), the contact force returns to static value approximatively $0.05 \mathrm{~s}$ after the perturbation caused by wheel defect. Analyzing the experimental data in Figure 8(a) it may be seen how the contact force maintains a periodical oscillation until next defect. This fact may be explained considering that the experimental data are affected by a minimum level of defects present on rail. A lower level of defect: $I_{l g}=6$ is applied to the rail to better represent this phenomenon. Looking at Figure 8(b) the simulation with rail defects seems to fit better experimental data. The lower and the upper pulsation in Table 2 are equivalent to ordinary values of long wavelength roughness $(2000 \mathrm{~mm})$ and medium wavelength roughness $(220 \mathrm{~mm})$ when train velocity is $70 \mathrm{~km} \mathrm{~h}^{-1}$. The number of defect functions seems to be not relevant after the value of 100 functions; X. Lei and N.A. Noda [9] suggested the value: $N=2500$.

\subsection{Case 3: corrugated rail (ISO3095 [22]) - Comparison with other numerical models}

In this case a rail with corrugation based on ISO3095 [22] is considered. The modal frequency analysis of the contact-force has been compared to results obtained by A. Johansson and J.C.O. Nielsen [26] model. The comparison between the models is shown in Figure 10. The highest amplitude of the Fourier spectrum of the normal contact-force corresponds to the passing frequency of the train on the sleeper, i.e. $85 \mathrm{~Hz}$. Focusing on Figure 10(b), amplitudes increase in magnitude around $600 \mathrm{~Hz}, 900 \mathrm{~Hz}$ and $1200 \mathrm{~Hz}$. These frequencies correspond to the bending modes of a rail, with pinned-pinned boundary conditions, considering the same length of the boogie wheelbase [27, 28]. Experimental results confirm this behavior [26].

\section{Sensitivity analysis}

A sensitivity analysis has been carried out to study the influence of each model variable on the output parameters. The output parameters selected for the analysis are the dynamic amplification factor of the wheel-rail contact force $\delta_{d y n}=R_{w / r} / R_{\text {static }}$ and the sleeper elastic deflection $z_{s l}$ ( $R_{\text {static }}$ is the vehicle weight divided by the number of wheels). The dynamic amplification factor is time dependent. The contact force $R_{w / r}$ varies around the static value during the simulation and, for certain time steps, assumes very high values. Anyway, these values are singular points and do not represent the total behaviour of contact-force during the whole time of simulation $T$. The following procedure has been conducted to choose a representative output parameter. The time simulation $T$ has been cut in $p$ ranges of time $\tau$. For each $g$-range the maximum value of the dynamic amplification factor $\delta_{d y n, g}$ has been evaluated for the third wheel from the left. In fact, the third wheel is the one less affected by boundary effects. Therefore the average between maximum values in all the time ranges has been calculated for every simulation. The procedure is summarized in Equation (13).

$$
\left\{\begin{array}{l}
\overline{\delta_{d y n}}=\sum_{g=1}^{p} \frac{\delta_{d y n, g}}{p} \\
p=\frac{T}{\tau} \\
\delta_{\text {dyn,g }}=\max \left[\frac{R_{w / r, 3}(t)}{R_{\text {static }}}\right] \quad t \in[(g-1) \tau,(g) \tau] ; g=1,2, \ldots, p .
\end{array}\right.
$$


The interval $\tau$ has been calculated as the time necessary to cover the transit of three sleepers. The sleeper distance used is 0,65 meters, so $\tau$ has been calculated as $2,3 \mathrm{~m} / V$, being $(3 \cdot 0,65 \mathrm{~m})<2,3 \mathrm{~m}$.

Many studies [29, 30, 31, 32, 33, 34] show how the ballast vertical settlement is proportional to the elastic deflection caused by each wheel pass and the number of applied wheel loads. Being ballast maintenance one of the most important costs for rail infrastructure operators, a sensitivity analysis of the sleeper deflection has been carried out. The sleeper chosen to check the maximum deflection value is the nearest one to the midpoint between the end of the railway length and the fourth wheel from the left. Among others, this sleeper is the one less affected by boundary effects. A OFAT model (one-factorat-a-time) is adopted to evaluate the sensitivity of parameters to all variables. The sensitivity index for each variable may be calculated with the standard regression coefficient [35] as:

$$
S R C_{i}=\frac{\beta_{i}^{2} V\left(X_{i}\right)}{V(Y)} \in[0,1]
$$

where the operator $V$ means variance of. The coefficient $\beta_{i}$, in case of a linear model, may be calculated as the ratio between the variation of the output parameter $\Delta Y$ and the increment of the variable $\Delta X_{i}$. In Figure 11, input parameters are ordered according their influence. It may be noticed the importance of train mass in both analyses. The ballast equivalent stiffness has a noticeable influence on the sleeper deflection but not on the dynamic amplification factor. Focusing on Figure 11(a), a significant outcome concerns the damping features of ballast, resulting less significant than pad damping. This behaviour is inverted for the ballast deflection (Figure 11(b)) where the ballast equivalent damping is more significant. Moreover in both analyses the wheel masses show a considerable influence.

\section{Conclusions and perspectives}

The model presented in this paper allows to predict contact force and vibrations in both vehicle and track components for a simplified vehicle model. The validation shows how predictions fit well experimental data. The introduced model of rail support is more accurate than past models for modal analysis of contact force and vibrations. The contact-area model is strongly recommended to evaluate the track receptance. The contact-point model provides satisfactory results as well, but produces considerably incorrect forecast in the pinned-pinned frequency range. The masses have a noticeable influence too, especially the vehicle and the wheel masses. The ballast equivalent stiffness results as the second important variable characterizing the sleeper elastic deflection. In future works we may include a flexible wheel-set instead of a single wheel mass; this will change the system response. The model could also be extended modeling a 3D contact including changes in the lateral position of the contact. 


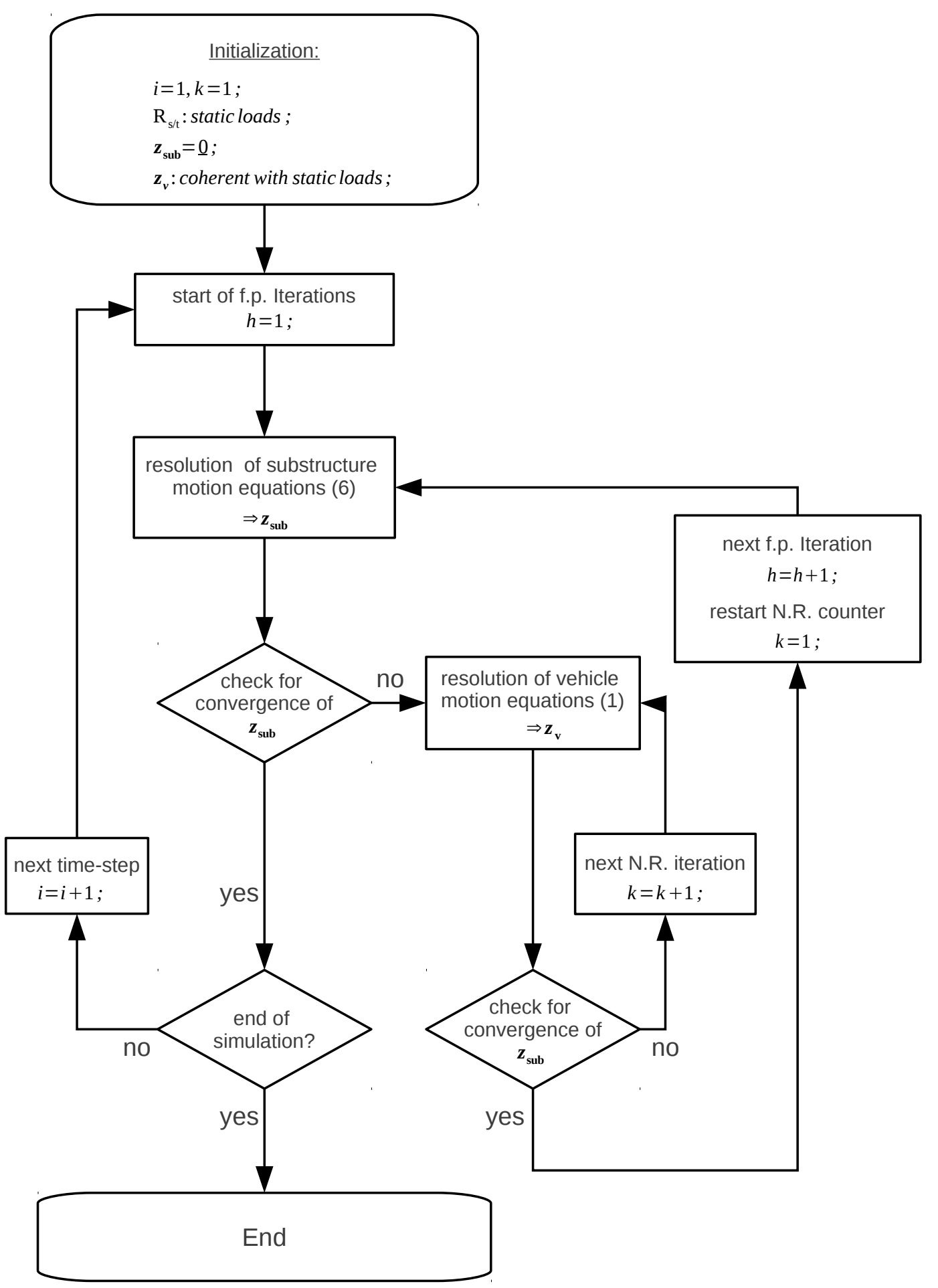

Figure 2: Algorithm of resolution. 

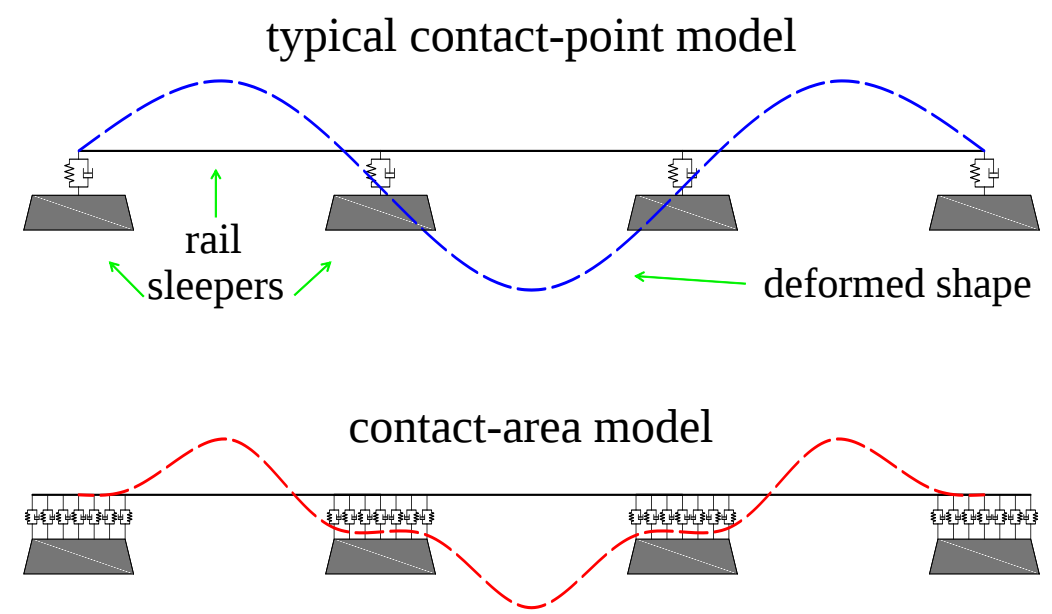

Figure 3: Draft of rail deformed shape in the case of the contact-point model and contact-area model.

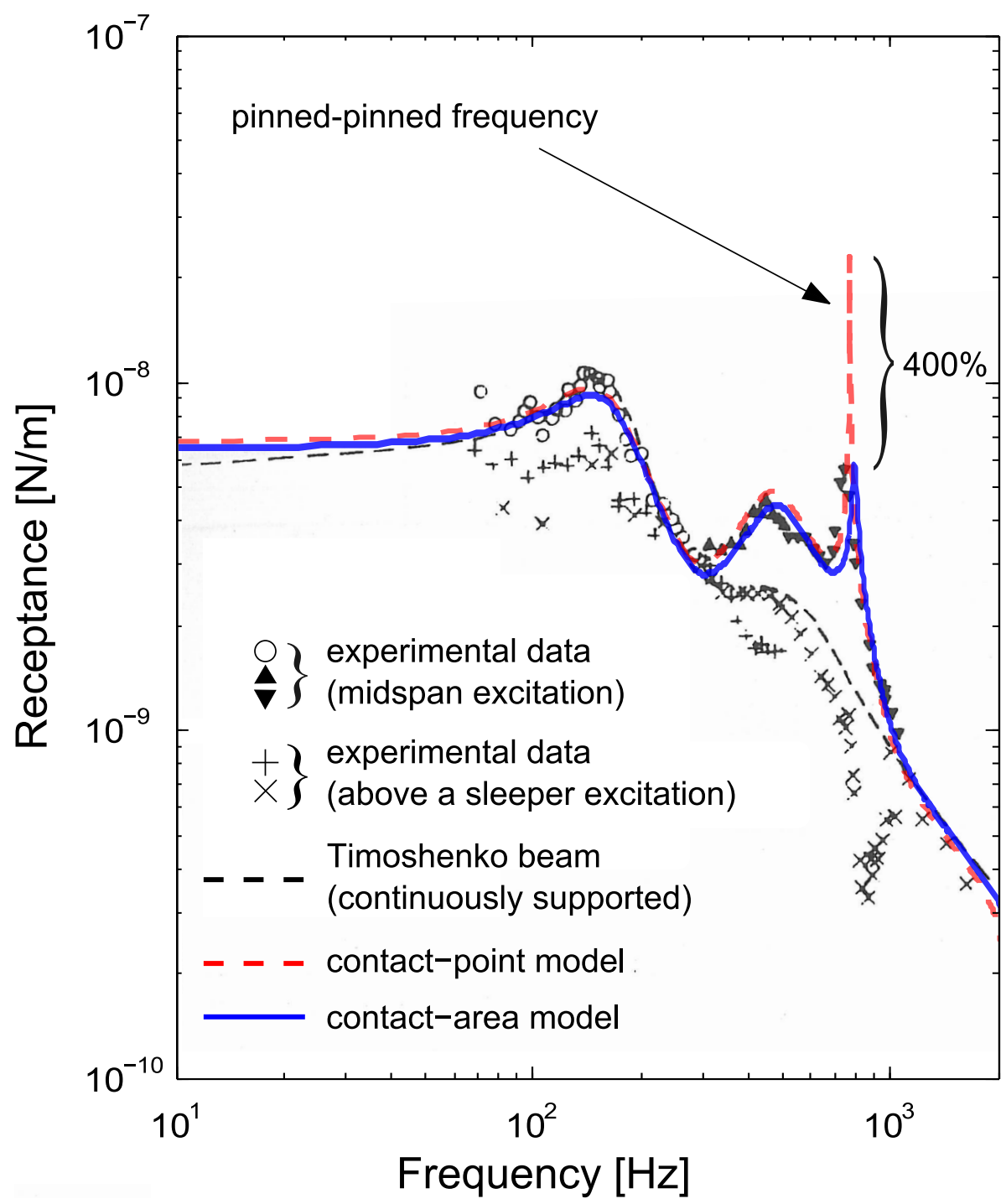

Figure 4: Comparison between receptances of the railway in the case of: the contact-point model, the contact-area model and experimental data [24]; case of midspan excitation. 


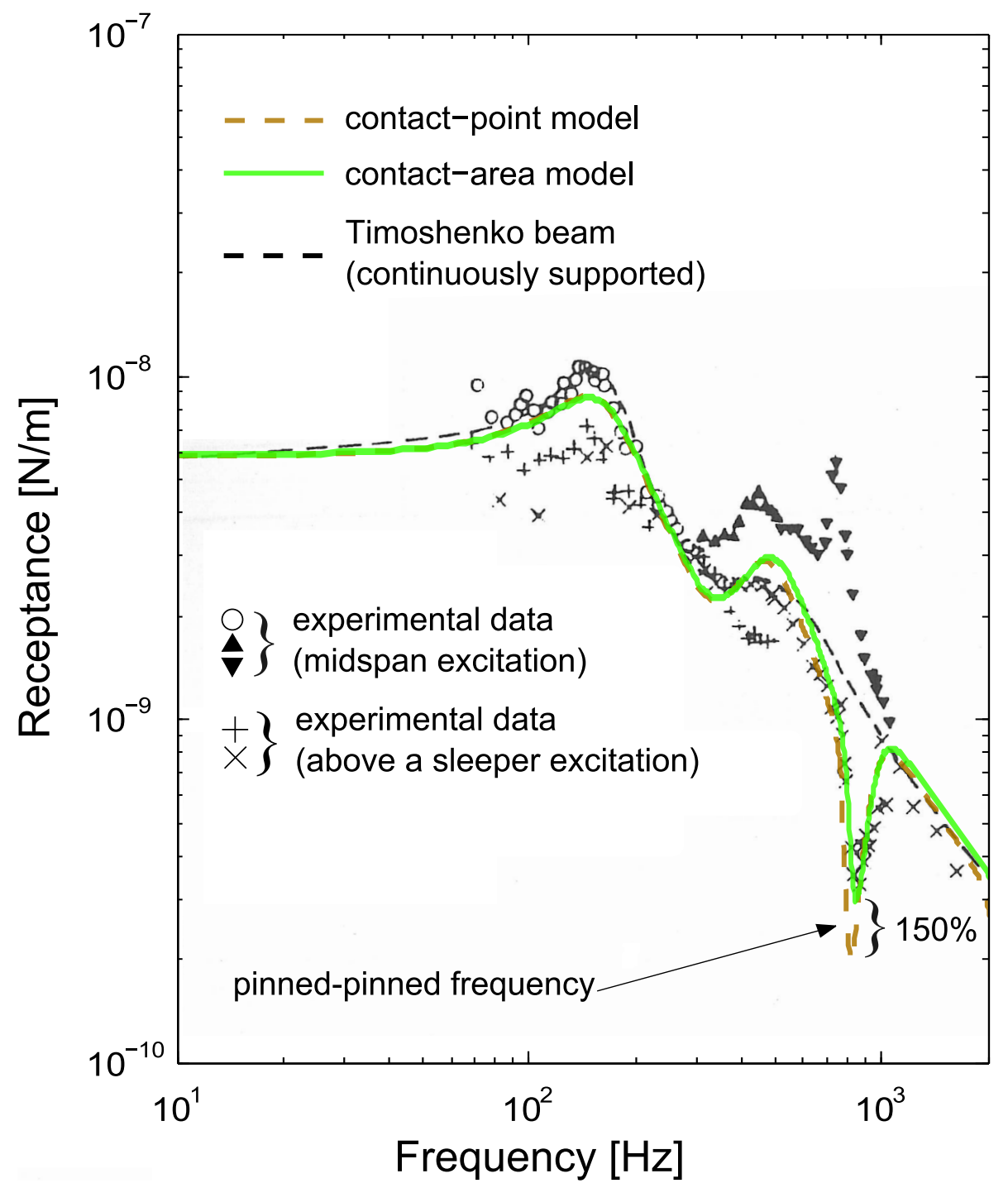

Figure 5: Comparison between receptances of the railway in the case of: the contact-point model, the contact-area model and experimental data [24]; case of on-sleeper excitation. 


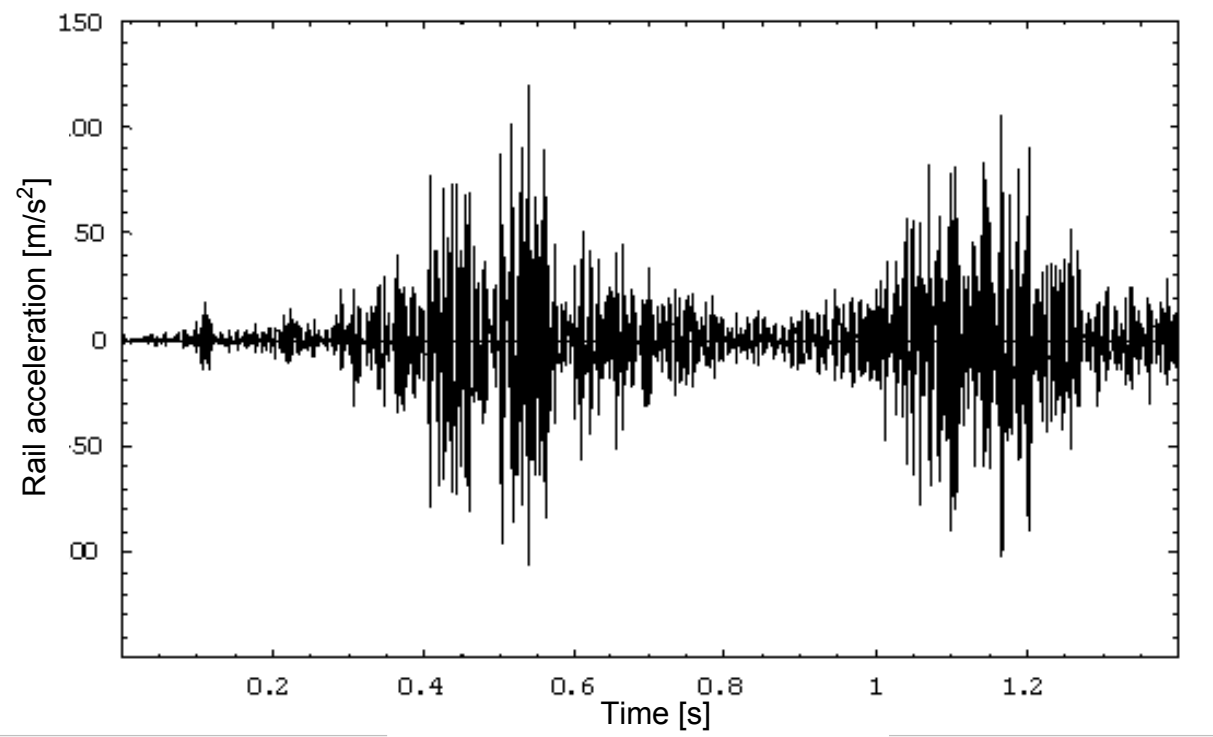

(a)

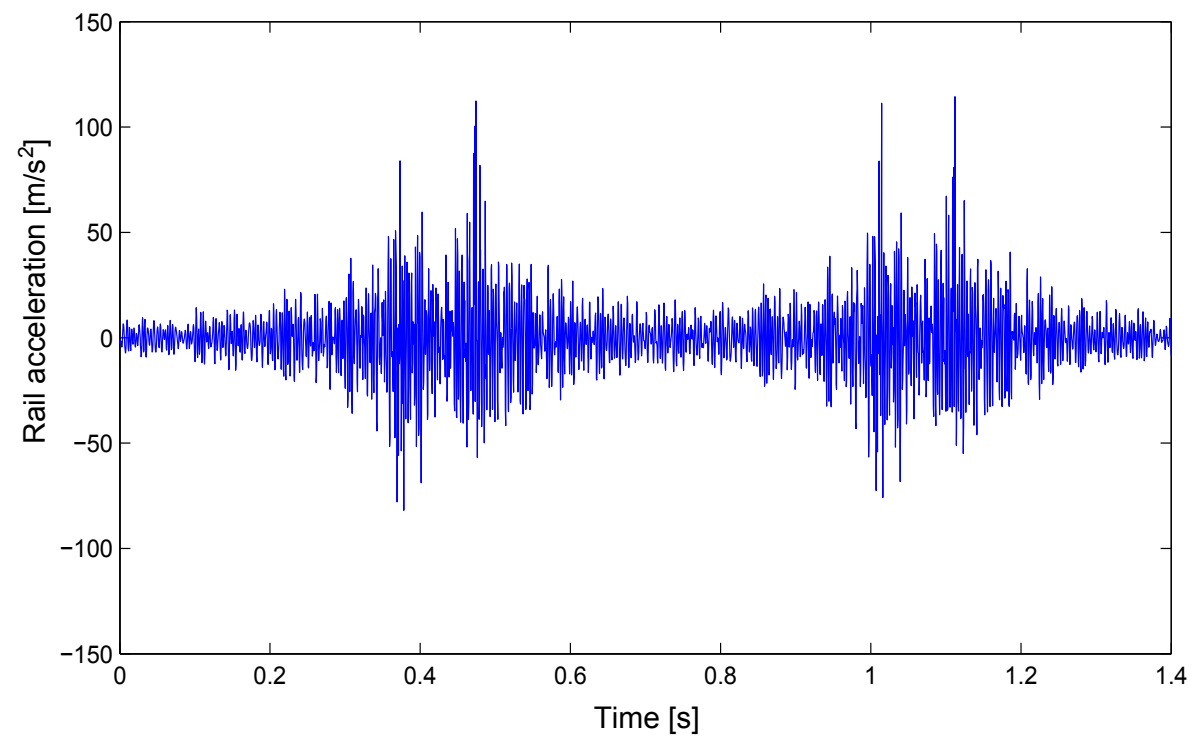

(b)

Figure 6: Comparison between: (a) experimental data [13] and (b) numerical results of the rail vertical acceleration in the case 1 . 


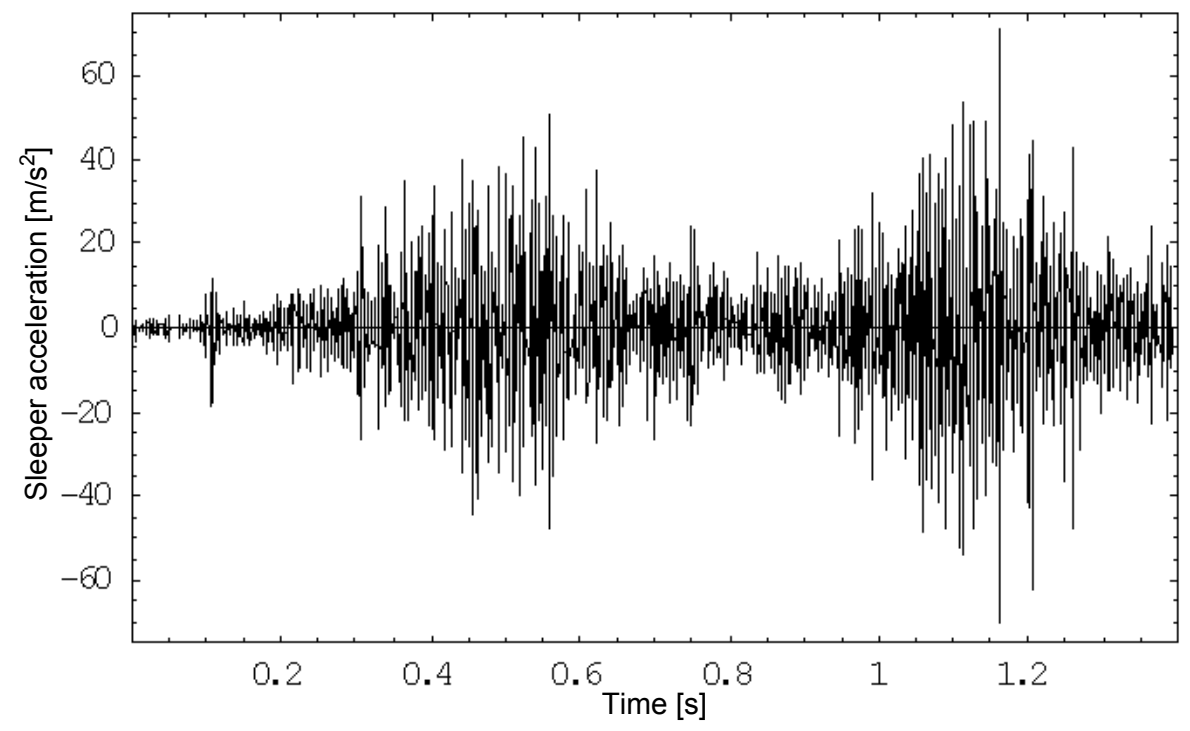

(a)

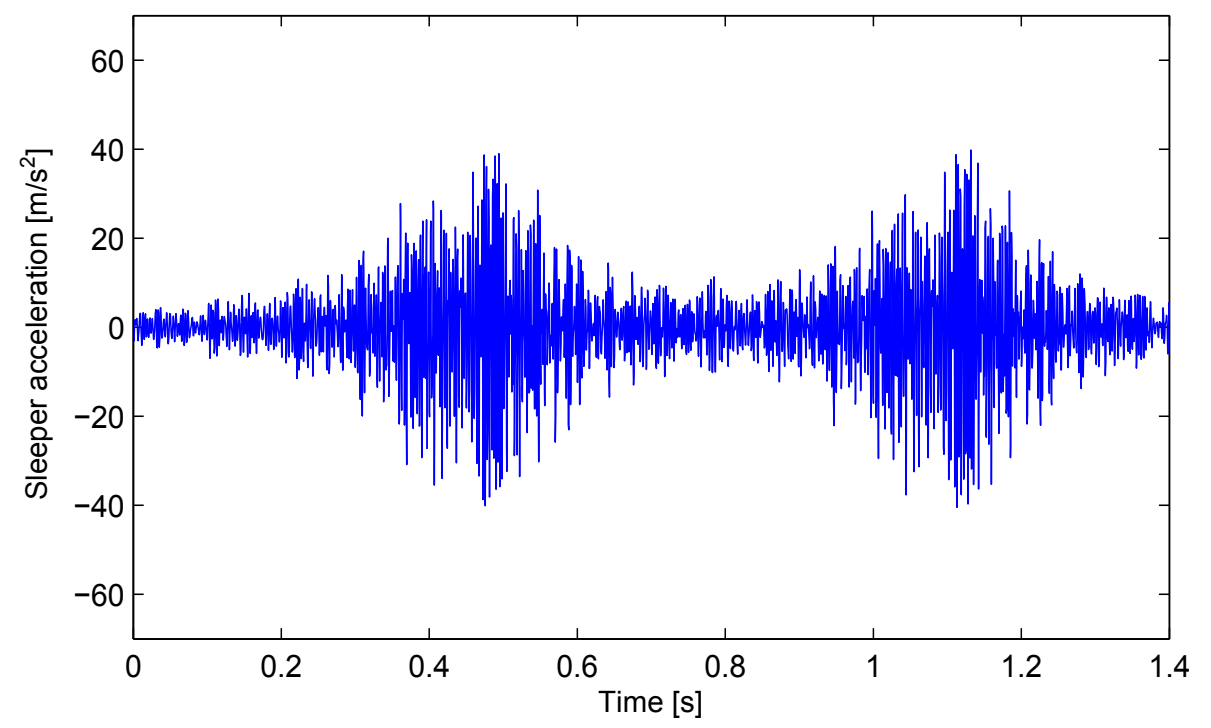

(b)

Figure 7: Comparison between: (a) experimental data [13] and (b) numerical results of the sleeper vertical acceleration in the case 1. 


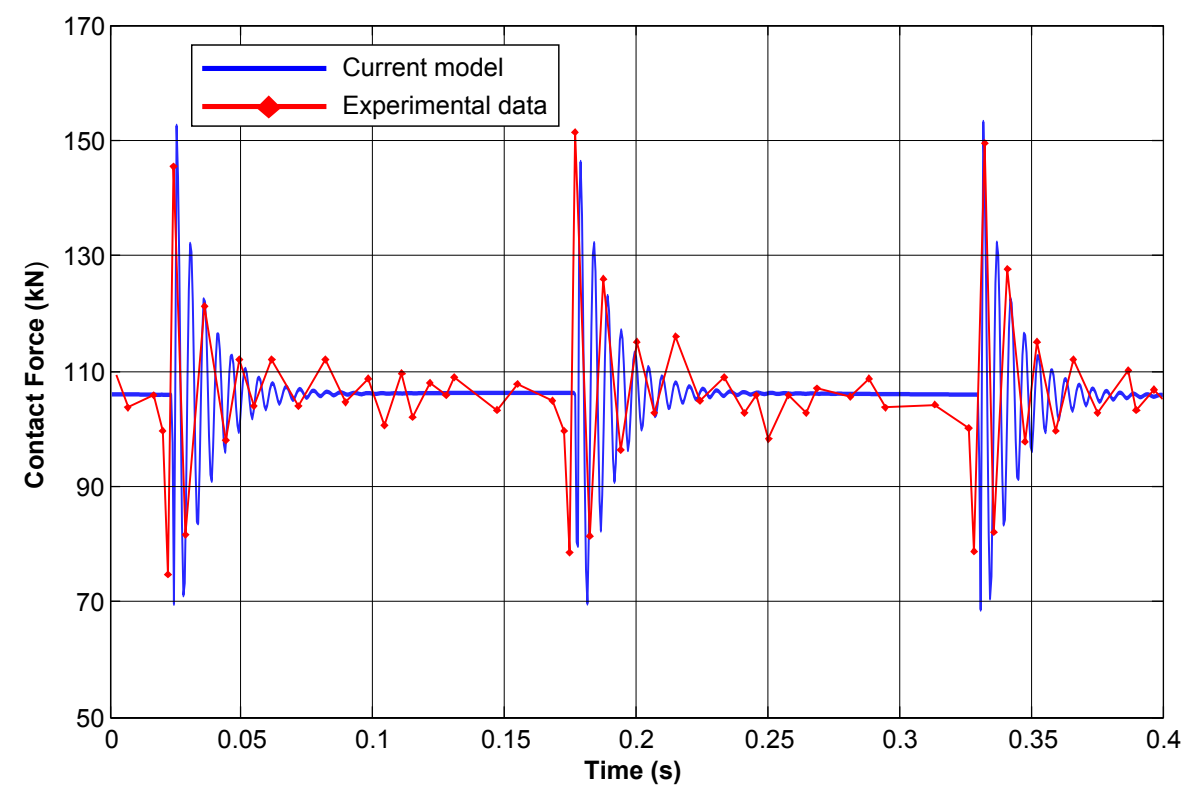

(a)

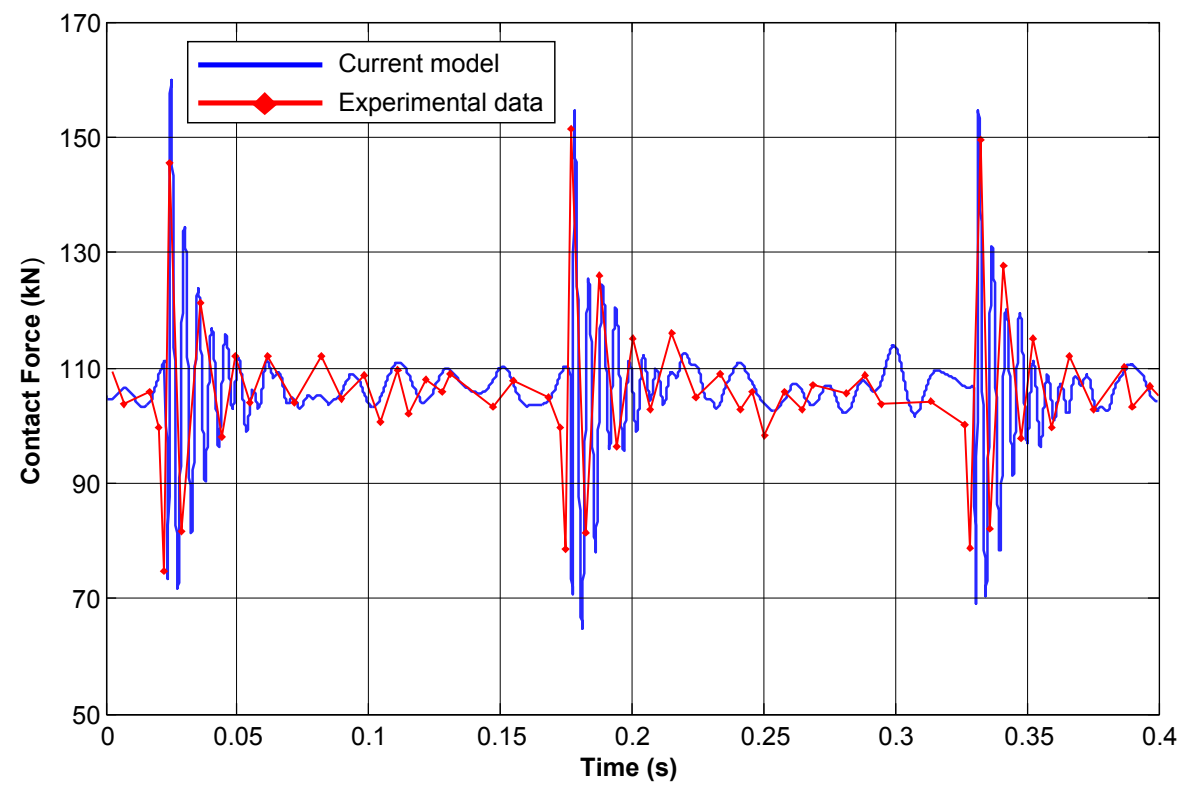

(b)

Figure 8: Comparison between experimental data [5] and numerical results for the case 2: (a) not including rail defects; (b) including rail defects. 


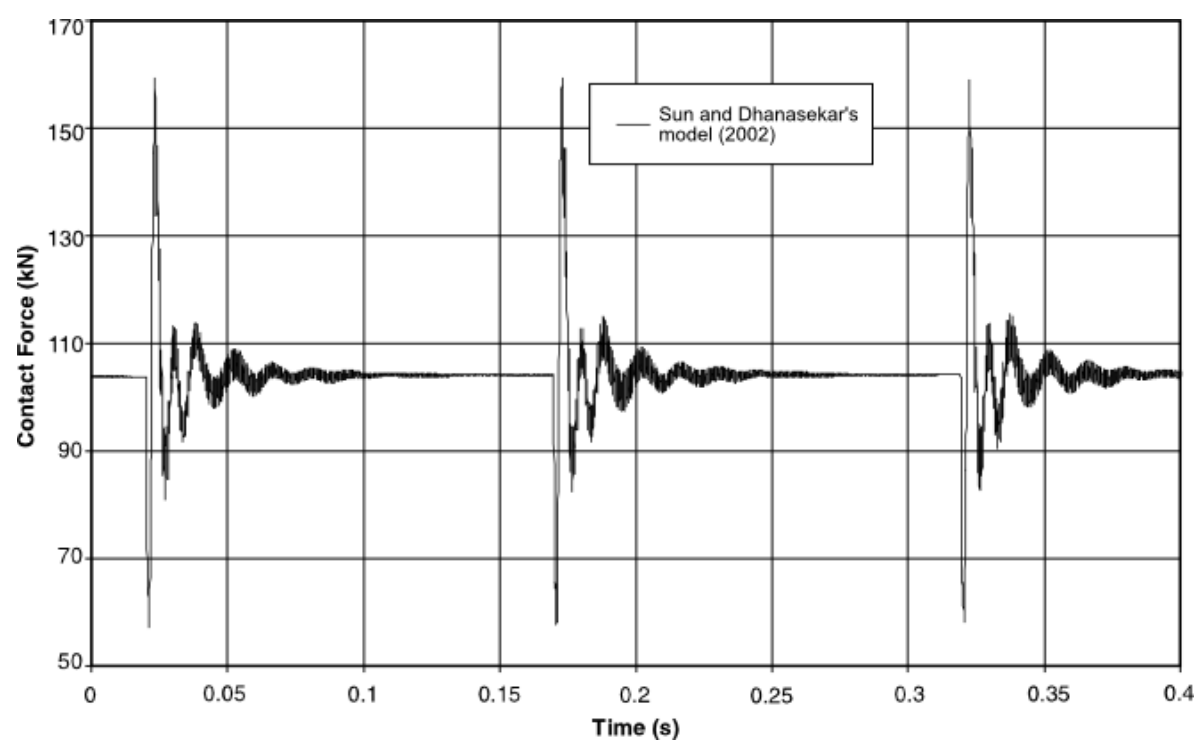

(a)

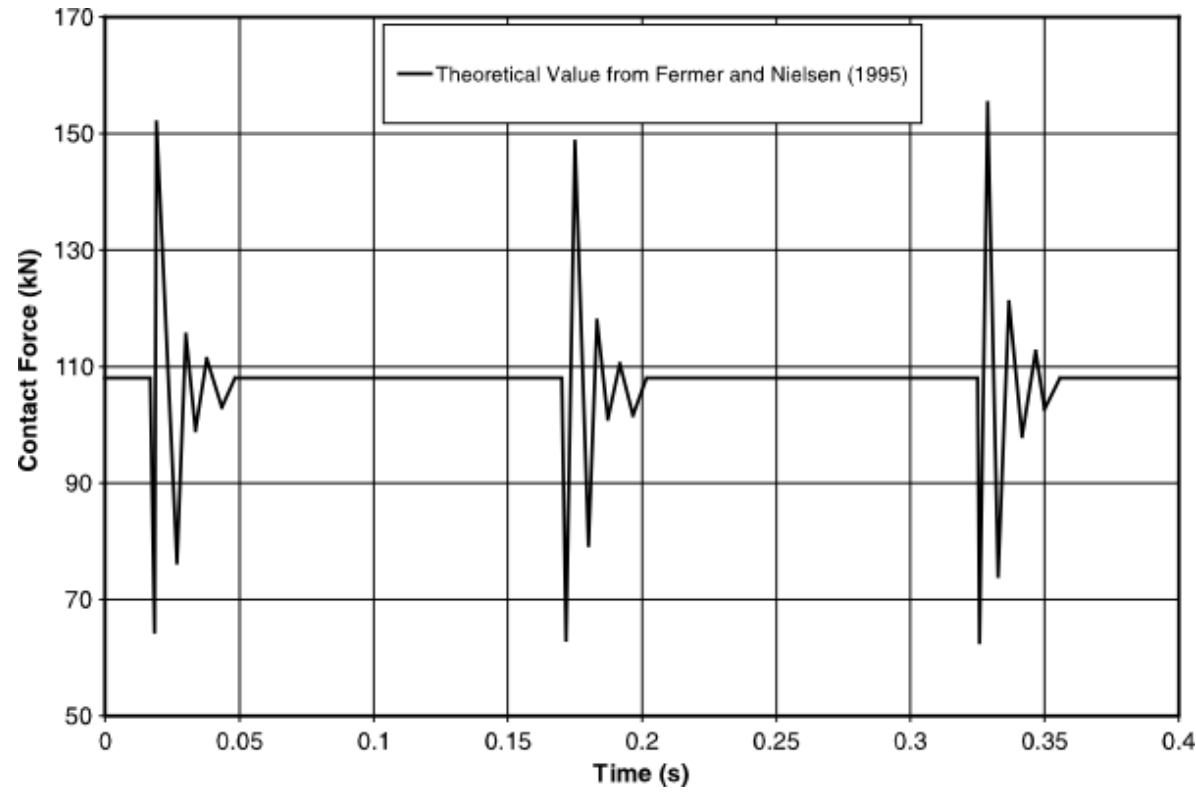

(b)

Figure 9: Numerical results of: (a) Sun and Dhanasekar[5]; (b) Fermer and Nielsen[25].

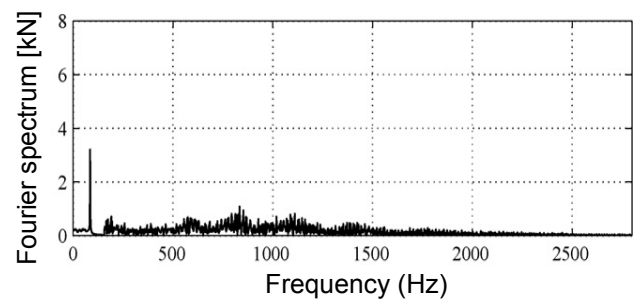

(a) Fourier spectrum of the normal contact force by Johansson \& Nielsen [26]

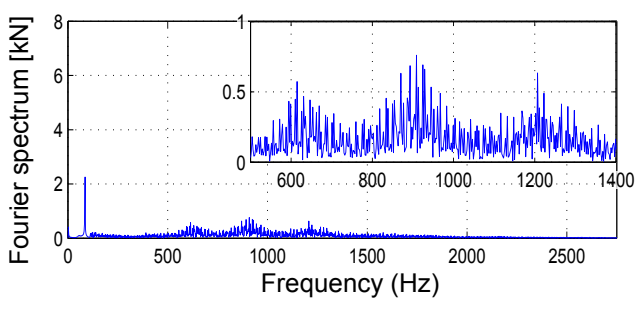

(b) Fourier spectrum of the normal contact-force calculated with our model

Figure 10: Comparison between A. Johansson and J.C.O. Nielsen [26] model and the proposed one in case of ISO3095 [22] based corrugation. 


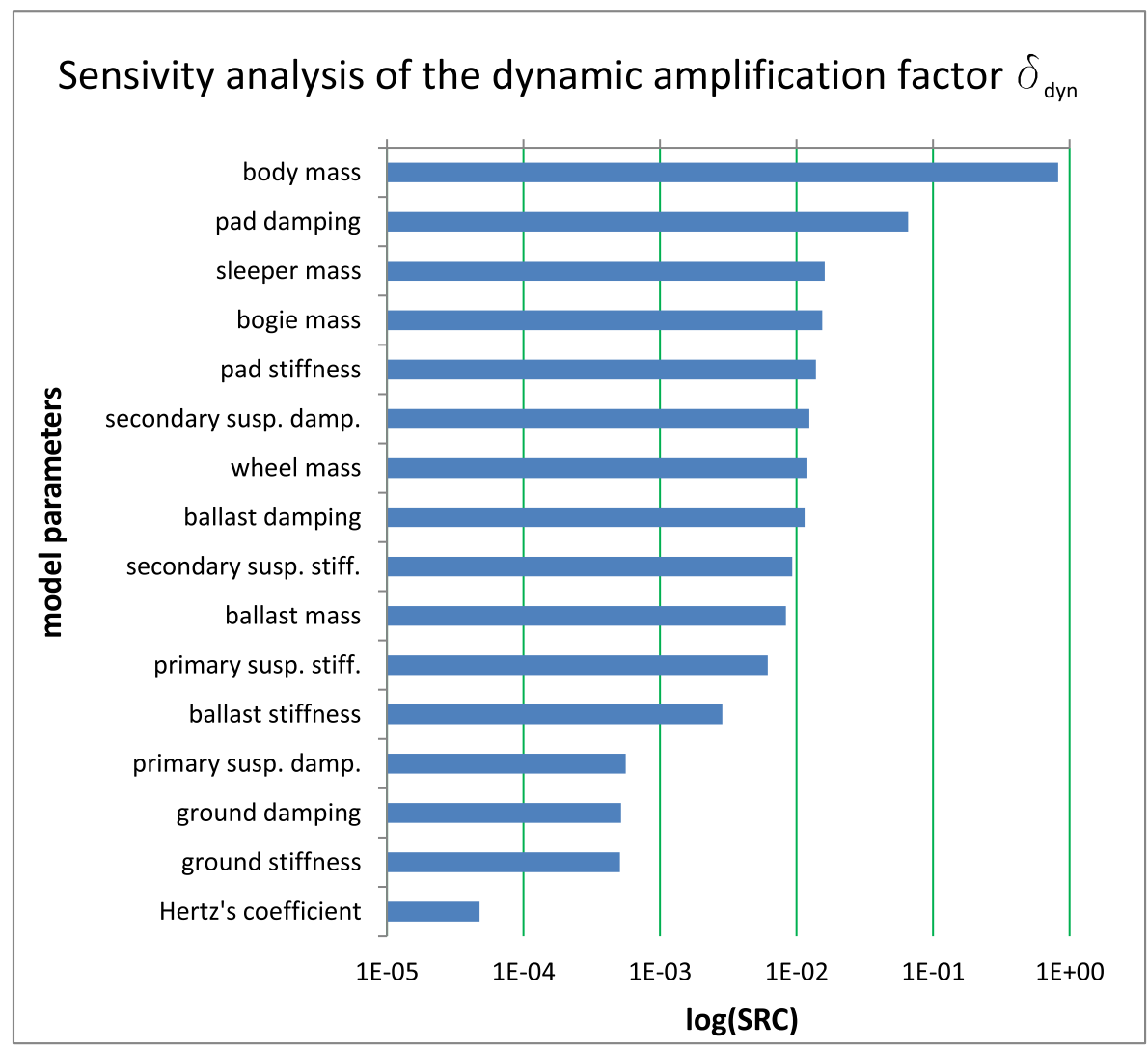

(a)

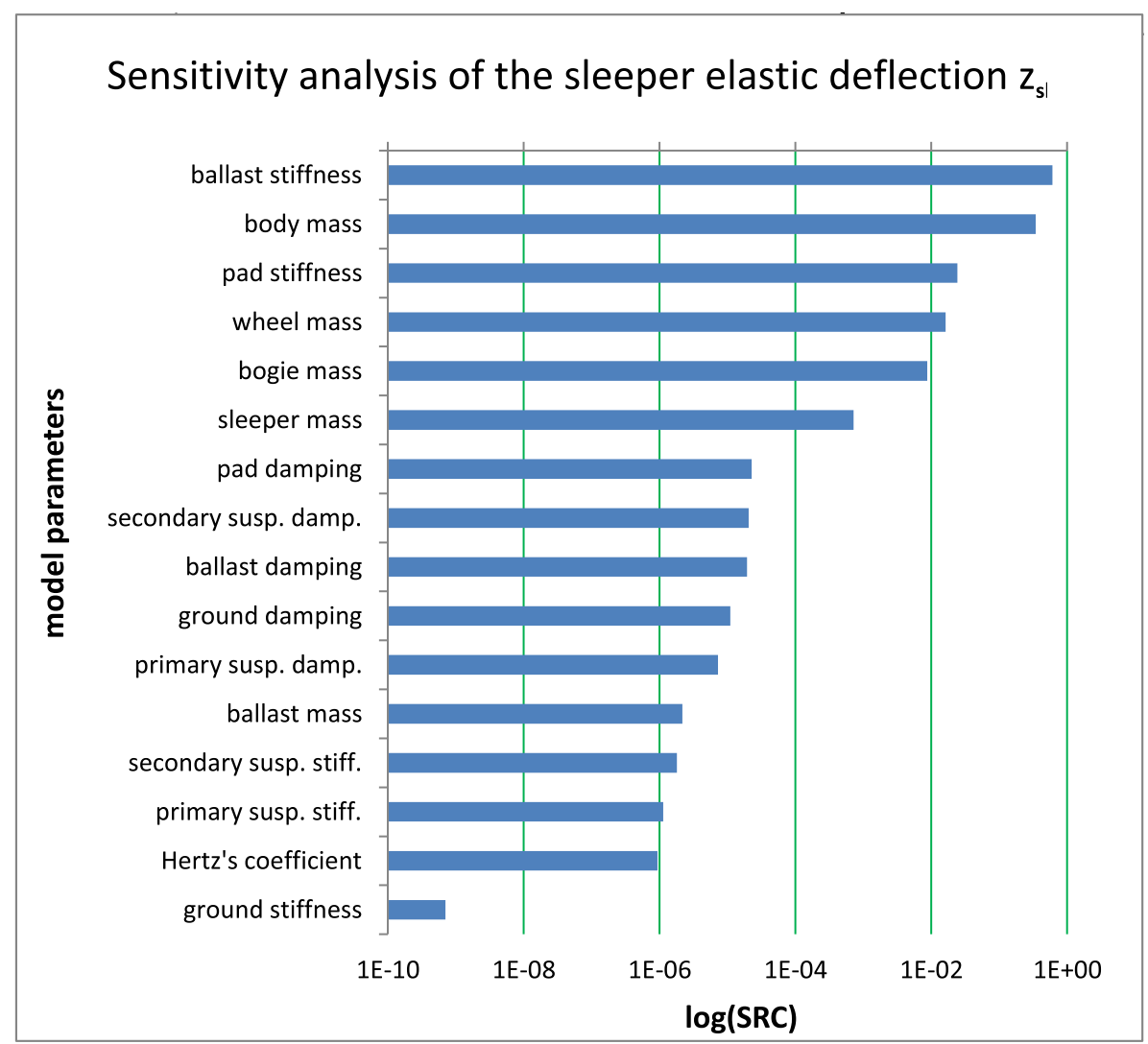

(b)

Figure 11: Sensivity analysis of: (a) the dynamic amplification factor; (b) the sleeper elastic deflection. 


\section{References}

[1] T. Ekevid, M.X.D. Li, and N.E. Wiberg, Adaptive FEA of wave propagation induced by high-speed trains, Computers and Structures 79 (2001), pp. $2693-2704$.

[2] A. Karlström, An analytical model for ground vibrations from accelerating trains, Journal of Sound and Vibration 293 (2006), pp. 587 - 598.

[3] A. Vostroukhov and A. Metrikine, Periodically supported beam on a visco-elastic layer as a model for dynamic analysis of a high-speed railway track, International Journal of Solids and Structures 40 (2003), pp. 5723 - 5752.

[4] J. Nielsen and A. Igeland, Vertical dynamic interaction between train and track influence of wheel and track imperfections, Journal of Sound and Vibration 187 (1995), pp. 825 - 839.

[5] Y.Q. Sun and M. Dhanasekar, A dynamic model for the vertical interaction of the rail track and wagon system, International Journal of Solids and Structures 39 (2002), pp. 1337 - 1359.

[6] J.C.O. Nielsen, High-frequency vertical wheel-rail contact forces - Validation of a prediction model by field testing, Wear 265 (2008), pp. 1465 - 1471.

[7] T. Mazilu, Prediction of the interaction between a simple moving vehicle and an infinite periodically supported rail — Green's functions approach, Vehicle System Dynamics 48 (2010), pp. 1021-1042.

[8] M.X. Li, E.G. Berggren, M. Berg, and I. Persson, Assessing track geometry quality based on wavelength spectra and trackvehicle dynamic interaction, Vehicle System Dynamics 46 (2008), pp. 261-276.

[9] X. Lei and N.A. Noda, Analyses of dynamic response of vehicle and track coupling system with random irregularity of track vertical profile, Journal of Sound and Vibration 258 (2002), pp. 147 165.

[10] F. Lu, D. Kennedy, F.W. Williams, and J.H. Lin, Symplectic analysis of vertical random vibration for coupled vehicletrack systems, Journal of Sound and Vibration 317 (2008), pp. 236 - 249.

[11] RFI, Specification (technical standard), Technical report, Rete Ferroviaria Italiana, 2011.

[12] W. Zhai and Z. Cai, Dynamic interaction between a lumped mass vehicle and a discretely supported continuous rail track, Computers and Structures 63 (1997), pp. 987 - 997.

[13] G. Di Mino, C. Di Liberto, and J. Nigrelli, A FEM model of rail track-ground system to calculate the ground borne vibrations: a case of rail track with wooden sleepers and $k$-fastenings at Castelvetrano, in Proceeding of Advanced Characterisation of Pavement and Soil Engineering Materials (2007), Athens, Greece, 2007.

[14] R. Ferrara, G. Leonardi, and F. Jourdan, Numerical Modelling of Train Induced Vibrations, Procedia - Social and Behavioral Sciences 53 (2012), pp. 155 - 165 SIIV-5th International Congress Sustainability of Road Infrastructures 2012.

[15] J.J. KALKER, Survey of Wheel-Rail Rolling Contact Theory, Vehicle System Dynamics 8 (1979), pp. 317-358.

[16] J. Pombo, J. Ambrósio, and M. Silva, A new wheelrail contact model for railway dynamics, Vehicle System Dynamics 45 (2007), pp. 165-189.

[17] J. Ayasse and H. Chollet, Determination of the wheel rail contact patch in semi-Hertzian conditions, Vehicle System Dynamics 43 (2005), pp. 161-172. 
[18] M. Machado, P. Moreira, P. Flores, and H.M. Lankarani, Compliant contact force models in multibody dynamics: Evolution of the Hertz contact theory, Mechanism and Machine Theory 53 (2012), pp. $99-121$.

[19] J.C.E. Pombo and J.A.C. Ambrósio, A multibody methodology for railway dynamics applications, Technical report, Instituto de Engenharia Mecanica, Instituto Superior Técnico, Av. Rovisco Pais, 1 1049-001 Lisboa, Portugal, 2004.

[20] J. Zhang, Q. Gao, S. Tan, and W. Zhong, A precise integration method for solving coupled vehicletrack dynamics with nonlinear wheelrail contact, Journal of Sound and Vibration 331 (2012), pp. $4763-4773$.

[21] W. Zhai, K. Wang, and J. Lin, Modelling and experiment of railway ballast vibrations, Journal of Sound and Vibration 270 (2004), pp. 673 - 683.

[22] A. Bracciali, Long roughness measurements - analysis and possible protocol, in 8th International Workshop on Railway Noise, Buxton, UK, 2009.

[23] M. Hiensch, J.C. Nielsen, and E. Verheijen, Rail corrugation in The Netherlands - measurements and simulations, Wear 253 (2002), pp. 140 - 149 CM2000 S.I.

[24] K. KNOTHE and S. GRASSIE, Modelling of Railway Track and Vehicle/Track Interaction at High Frequencies, Vehicle System Dynamics 22 (1993), pp. 209-262.

[25] M. Fermér and J.C.O. Nielsen, Vertical interaction between train and track with soft and stiff rail pads - full-scale experiments and theory, in Proceeding of the Institution of Mechanical Engineers (1995), Vol. 209, 1995, pp. $39-47$.

[26] A. Johansson and J.C. Nielsen, Rail corrugation growth - Influence of powered wheelsets with wheel tread irregularities, Wear 262 (2007), pp. 1296-1307.

[27] A. Igeland, Rail corrugation growth explained by interaction between track and bogie wheelsets, in the Institution of Mechanical Engineers, Vol. part F 210 (1), 1996, pp. 11-20.

[28] T. Wu and D. Thompson, An investigation into rail corrugation due to micro-slip under multiple wheel/rail interactions, Wear 258 (2005), pp. 1115 - 1125 Contact Mechanics and Wear of Rail/Wheel Systems.

[29] V. Bodin-Bourgoin, P. Tamagny, K. Sab, and P. Gautier, Détermination expérimentale d'une loi de tassement du ballast des voies ferrées soumises à un chargement latéral, Canadian Geotechnical Journal 43 (2006), pp. 1028-1041.

[30] C. Paderno, Comportement du ballast sous l'action du bourrage et du trafic ferroviaire, ENAC, Lausanne, 2010, PhD thesis.

[31] G. Saussine, Contribution à la modélisation de granulats tridimensionnels: application au ballast, LMGC - Laboratoire de mécanique et génie civil, Montpellier, 2004, PhD thesis.

[32] N. Guerin, Approche expérimentale et numérique du comportement du ballast des voies ferrées, Ecole Des Ponts Paristech, Paris, 2010, PhD thesis.

[33] M. Abdelkrim, Analyse par le calcul des structures du comportement cyclique à long terme des infrastructures de transport, Ecole Des Ponts Paristech, Paris, 2001, PhD thesis.

[34] M. Abdelkrim, G. Bonnet, and P. Buhande, A computational procedure for predicting the long term residual settlement of a platform induced by repeated traffic loading, Computers and Geotechnics 30 (2003), pp. $463-476$. 
[35] J. Jacques, 2011, 71-III. in Pratique de l'analyse de sensibilité: comment évaluer l'impact des entrées aléatoires sur la sortie d'un modèle mathématique IRMA, Lille.

\section{A Vehicle matrices}

The displacement vector $\mathbf{z}_{v}$, the forces vector $\mathbf{f}_{v}$, the mass matrix $\mathbf{M}_{v}$, the stiffness matrix $\mathbf{K}_{v}$ and the damping matrix $\mathbf{C}_{v}$ are here defined:

$$
\begin{aligned}
& \mathbf{z}_{v}=\left[\begin{array}{c}
z_{c} \\
\phi_{c} \\
z_{t} \\
\phi_{t} \\
z_{t} \\
\phi_{t} \\
z_{w_{1}} \\
z_{w_{2}} \\
z_{w_{3}} \\
z_{w_{4}}
\end{array}\right]_{10 \times 1}, \mathbf{q}_{v}=\left[\begin{array}{c}
m_{c} g \\
0 \\
m_{t} g \\
0 \\
m_{t} g \\
0 \\
m_{w} g \\
m_{w} g \\
m_{w} g \\
m_{w} g
\end{array}\right]_{10 \times 1} \quad, \quad \mathbf{f}_{v}=\left[\begin{array}{c}
0 \\
0 \\
0 \\
0 \\
0 \\
0 \\
R_{r / w_{1}} \\
R_{r / w_{2}} \\
R_{r / w_{3}} \\
R_{r / w_{4}}
\end{array}\right]_{10 \times 1} \\
& \mathbf{M}_{v}=\operatorname{diag}\left[\begin{array}{llllllllll}
m_{c} & J_{c} & m_{t} & J_{t} & m_{t} & J_{t} & m_{w} & m_{w} & m_{w} & m_{w}
\end{array}\right]_{10 \times 10}, \\
& \mathbf{K}_{v}=\left[\begin{array}{cccccccccc}
2 k_{2} & 0 & -k_{2} & 0 & -k_{2} & 0 & 0 & 0 & 0 & 0 \\
0 & 2 k_{2} l_{t}^{2} & -k_{2} l_{t} & 0 & k_{2} l_{t} & 0 & 0 & 0 & 0 & 0 \\
-k_{2} & -k_{2} l_{t} & k_{2}+2 k_{1} & 0 & 0 & 0 & -k_{1} & -k_{1} & 0 & 0 \\
0 & 0 & 0 & 2 k_{1} l_{w}^{2} & 0 & 0 & -k_{1} l_{w} & k_{1} l_{w} & 0 & 0 \\
-k_{2} & k_{2} l_{t} & 0 & 0 & k_{2}+2 k_{1} & 0 & 0 & 0 & -k_{1} & -k_{1} \\
0 & 0 & 0 & 0 & 0 & 2 k_{1} l_{w}^{2} & 0 & 0 & -k_{1} l_{w} & k_{1} l_{w} \\
0 & 0 & -k_{1} & -k_{1} l_{w} & 0 & 0 & k_{1} & 0 & 0 & 0 \\
0 & 0 & -k_{1} & -k_{1} l_{w} & 0 & 0 & 0 & k_{1} & 0 & 0 \\
0 & 0 & 0 & 0 & -k_{1} & -k_{1} l_{w} & 0 & 0 & k_{1} & 0 \\
0 & 0 & 0 & 0 & -k_{1} & -k_{1} l_{w} & 0 & 0 & 0 & k_{1}
\end{array}\right]_{10 \times 10} \\
& \mathbf{C}_{v}=\left[\begin{array}{cccccccccc}
2 c_{2} & 0 & -c_{2} & 0 & -c_{2} & 0 & 0 & 0 & 0 & 0 \\
0 & 2 c_{2} l_{t}^{2} & -c_{2} l_{t} & 0 & c_{2} l_{t} & 0 & 0 & 0 & 0 & 0 \\
-c_{2} & -c_{2} l_{t} & c_{2}+2 c_{1} & 0 & 0 & 0 & -c_{1} & -c_{1} & 0 & 0 \\
0 & 0 & 0 & 2 c_{1} l_{w}^{2} & 0 & 0 & -c_{1} l_{w} & c_{1} l_{w} & 0 & 0 \\
-c_{2} & c_{2} l_{t} & 0 & 0 & c_{2}+2 c_{1} & 0 & 0 & 0 & -c_{1} & -c_{1} \\
0 & 0 & 0 & 0 & 0 & 2 c_{1} l_{w}^{2} & 0 & 0 & -c_{1} l_{w} & c_{1} l_{w} \\
0 & 0 & -c_{1} & -c_{1} l_{w} & 0 & 0 & c_{1} & 0 & 0 & 0 \\
0 & 0 & -c_{1} & -c_{1} l_{w} & 0 & 0 & 0 & c_{1} & 0 & 0 \\
0 & 0 & 0 & 0 & -c_{1} & -c_{1} l_{w} & 0 & 0 & c_{1} & 0 \\
0 & 0 & 0 & 0 & -c_{1} & -c_{1} l_{w} & 0 & 0 & 0 & c_{1}
\end{array}\right]_{10 \times 10}
\end{aligned}
$$

where $2 l_{w}$ is the wheelbase and $2 l_{t}$ is the distance between the bogies pivot points.

\section{B Assembling motion equations for the substructure}

In order to simplify the resolution of the track/vehicle system, motion equations of substructure are unified in matrix form by assembling equations of rail, sleepers and ballast blocks. The motion equation 
for the $m^{t h}$ sleeper (see Figure 1) is

$$
m_{s} \ddot{z}_{s}+\left(c_{b}+c_{p}\right) \dot{z}_{s}+\left(k_{b}+k_{p}\right) z_{s}-c_{b} \dot{z}_{b}-k_{b} z_{b}-\frac{c_{p}}{n} \sum_{p=1}^{n} \dot{z}_{r}-\frac{k_{p}}{n} \sum_{p=1}^{n} z_{r}=m_{s} g ;
$$

the motion equation for the $m^{\text {th }}$ ballast block is ${ }^{4}$

$$
\begin{aligned}
m_{b} \ddot{z}_{b}+\left(2 c_{w}+c_{b}+c_{f}\right) \dot{z}_{b}+\left(2 k_{w}+k_{b}+k_{f}\right) z_{b}-c_{w} \dot{z}_{b_{i+1}}+ & \\
& -c_{w} \dot{z}_{b_{i-1}}-k_{w} z_{b_{i+1}}-k_{w} z_{b_{i-1}}-c_{b} \dot{z}_{s}-k_{b} z_{s}=m_{b} g .
\end{aligned}
$$

Assembling all equations, in the matrix form:

$$
\mathbf{M}_{s u b} \ddot{\mathbf{z}}_{s u b}+\mathbf{C}_{s u b} \dot{\mathbf{z}}_{s u b}+\mathbf{K}_{s u b} \mathbf{z}_{s u b}=\mathbf{q}_{s u b}+\mathbf{f}_{s u b},
$$

where $\mathbf{M}_{s u b}$ is the assembled mass matrix of substructure:

$$
\mathbf{M}_{s u b}=\left[\begin{array}{lll}
\mathbf{M}_{r} & \mathbf{0}_{2 n \times m} & \mathbf{0}_{2 n \times m} \\
\mathbf{0}_{m \times 2 n} & \mathbf{M}_{s} & \mathbf{0}_{m \times m} \\
\mathbf{0}_{m \times 2 n} & \mathbf{0}_{m \times m} & \mathbf{M}_{b}
\end{array}\right]_{(2 n+2 m) \times(2 n+2 m)}
$$

in which the sub-matrices $\mathbf{M}_{s}$ and $\mathbf{M}_{b}$ are

$$
\begin{aligned}
& \mathbf{M}_{s}=\operatorname{diag}\left[\begin{array}{lll}
m_{s} & \cdots & m_{s}
\end{array}\right]_{m \times m} ; \\
& \mathbf{M}_{b}=\operatorname{diag}\left[\begin{array}{lll}
m_{b} & \cdots & m_{b}
\end{array}\right]_{m \times m} ;
\end{aligned}
$$

$\mathbf{K}_{s u b}$ is the assembled stiffness matrix of substructure:

$$
\mathbf{K}_{s u b}=\left[\begin{array}{lll}
\mathbf{K}_{r} & \mathbf{B}^{T} & \mathbf{0}_{2 n \times m} \\
\mathbf{B} & \mathbf{K}_{s} & \mathbf{D} \\
\mathbf{0}_{m \times 2 n} & \mathbf{D} & \mathbf{K}_{b}
\end{array}\right]_{(2 n+2 m) \times(2 n+2 m)}
$$

in which sub-matrices $\mathbf{B}, \mathbf{K}_{s}, \mathbf{D}$ and $\mathbf{K}_{b}$ are defined $^{5}$ as

$$
\begin{aligned}
& \mathbf{B}=\left[\begin{array}{cccccccccc}
-k_{p} & 0 & 0 & 0 & 0 & 0 & \cdots & \cdots & \cdots & 0 \\
0 & 0 & 0 & 0 & -k_{p} & 0 & \cdots & \cdots & \cdots & 0 \\
0 & 0 & 0 & 0 & 0 & 0 & \ddots & \ddots & \ddots & \vdots \\
\vdots & \vdots & \vdots & \vdots & \vdots & \vdots & \ddots & \ddots & \ddots & \vdots \\
0 & 0 & 0 & 0 & 0 & 0 & \cdots & 0 & -k_{p} & 0
\end{array}\right]_{m \times 2 n} \\
& \mathbf{K}_{s}=\operatorname{diag}\left[\begin{array}{lll}
k_{b}+k_{p} & \cdots & k_{b}+k_{p}
\end{array}\right]_{m \times m}, \\
& \mathbf{D}=\operatorname{diag}\left[\begin{array}{lll}
-k_{b} & \cdots & -k_{b}
\end{array}\right]_{m \times m} \quad, \\
& \mathbf{K}_{b}=\left[\begin{array}{ccccccc}
k_{w b f}^{\prime} & -k_{w} & 0 & \cdots & \cdots & \cdots & 0 \\
-k_{w} & k_{w b f} & -k_{w} & 0 & \cdots & \cdots & 0 \\
0 & -k_{w} & k_{w b f} & -k_{w} & 0 & \cdots & 0 \\
\vdots & 0 & -k w & \ddots & \ddots & \ddots & \vdots \\
\vdots & \vdots & 0 & \ddots & \ddots & \ddots & 0 \\
\vdots & \vdots & \vdots & \ddots & \ddots & k_{w b f} & -k_{w} \\
0 & 0 & 0 & \cdots & 0 & -k w & k_{w b f}^{\prime}
\end{array}\right]_{m \times m}
\end{aligned}
$$

\footnotetext{
${ }^{4}$ The equation is written considering a generic ballast block connected horizontally with next and previous block. An exception has to be done for boundary condition in which $i+1$ and $i-1$ terms in (20) are nulls.

${ }^{5}$ Sub-matrix $\mathbf{B}$ shown in this example is written for simplicity considering only two beams between sleepers.
} 
where $k_{w b f}^{\prime}=k_{w}+k_{b}+k_{f}$ and $k_{w b f}=2 k_{w}+k_{b}+k_{f}$;

$\mathbf{C}_{s u b}$ is the assembled damping matrix written as $\mathbf{K}_{\text {sub }}$ but substituting $k$ terms with correspondent $c$ terms;

$\mathbf{Z}_{\text {sub }}$ is the assembled vector of displacements and rotations:

$$
\mathbf{Z}_{\text {sub }}=\left[\begin{array}{c}
\mathbf{z}_{r} \\
\mathbf{z}_{s} \\
\mathbf{z}_{b}
\end{array}\right]_{(2 n+2 m) \times 1}
$$

in which $\mathbf{z}_{s}$ and $\mathbf{z}_{b}$ are defined as

$$
\begin{aligned}
& \mathbf{z}_{s}=\left[\begin{array}{lllll}
z_{s_{1}} & \cdots & z_{s_{i}} & \cdots & z_{s_{m}}
\end{array}\right]_{m \times 1}^{T}, \\
& \mathbf{z}_{b}=\left[\begin{array}{lllll}
z_{b_{1}} & \cdots & z_{b_{i}} & \cdots & z_{b_{m}}
\end{array}\right]_{m \times 1}^{T} ;
\end{aligned}
$$

$\mathbf{q}_{s u b}$ and $\mathbf{f}_{s u b}$ are the assembled forces vector:

$$
\mathbf{f}_{s u b}+\mathbf{q}_{s u b}=\left[\begin{array}{c}
\mathbf{f}_{r} \\
\mathbf{0} \\
\mathbf{0}
\end{array}\right]_{(2 n+2 m) \times 1}+\left[\begin{array}{l}
\mathbf{q}_{r} \\
\mathbf{q}_{s} \\
\mathbf{q}_{b}
\end{array}\right]_{(2 n+2 m) \times 1},
$$

where $\mathbf{q}_{s}$ and $\mathbf{q}_{b}$ are defined as

$$
\mathbf{q}_{s}=m_{s} \mathbf{i}_{m \times 1}, \quad \mathbf{q}_{b}=m_{b} \mathbf{i}_{m \times 1},
$$

and $\mathbf{i}_{m \times 1}$ is a vector where all components are one. 


\section{Model parameters}

Table 1: Model parameters adopted for the simulation in first railway line.

Case 1

\begin{tabular}{|c|c|c|c|}
\hline notation & parameter & value & unit \\
\hline & Model parameters of substructure ${ }^{a}$ & & \\
\hline$E$ & young modulus of rail & $2.07 \cdot 10^{11}$ & $\mathrm{Nm}^{-1}$ \\
\hline$I$ & inertial modulus of rail & $1884 \cdot 10^{-8}$ & $\mathrm{~m}^{4}$ \\
\hline$A$ & section area of rail & $63.62 \cdot 10^{-4}$ & $\mathrm{~m}^{2}$ \\
\hline$\chi$ & Timoshenko shear coefficient & 0.34 & \\
\hline$m_{r}$ & railway mass (per unit length) & 49.9 & $\mathrm{~kg} \mathrm{~m}^{-1}$ \\
\hline$M_{s}$ & sleeper mass & 33 & $\mathrm{~kg}$ \\
\hline$M_{b}$ & ballast mass & 700 & $\mathrm{~kg}$ \\
\hline$k_{p}$ & pad stiffness & $26.5 \cdot 10^{7}$ & $\mathrm{Nm}^{-1}$ \\
\hline$c_{p}$ & pad damping & $40 \cdot 10^{3}$ & $\mathrm{~N} \mathrm{~s} \mathrm{~m}^{-1}$ \\
\hline$k_{b}$ & ballast stiffness & $24 \cdot 10^{7}$ & $\mathrm{~N} \mathrm{~m}^{-1}$ \\
\hline$c_{b}$ & ballast damping & $58.8 \cdot 10^{3}$ & $\mathrm{~N} \mathrm{~s} \mathrm{~m}^{-1}$ \\
\hline$k_{w}$ & horizontal stiffness & $7.84 \cdot 10^{7}$ & $\mathrm{~N} \mathrm{~m}^{-1}$ \\
\hline$c_{w}$ & horizontal damping & $80 \cdot 10^{3}$ & $\mathrm{~N} \mathrm{~s} \mathrm{~m}^{-1}$ \\
\hline$k_{f}$ & subgrade stiffness & $7.68 \cdot 10^{7}$ & $\mathrm{Nm}^{-1}$ \\
\hline$c_{f}$ & subgrade damping & $64.6 \cdot 10^{3}$ & $\mathrm{~N} \mathrm{~s} \mathrm{~m}^{-1}$ \\
\hline \multirow[t]{2}{*}{$l_{s}$} & sleeper base & 65 & $\mathrm{~cm}$ \\
\hline & Model parameters of train $A \ln 668^{a}$ & & \\
\hline $2 M_{c}$ & car body mass & 28800 & $\mathrm{~kg}$ \\
\hline$M_{b}$ & bogie mass & 3600 & $\mathrm{~kg}$ \\
\hline $2 M_{w}$ & wheelset mass & 500 & $\mathrm{~kg}$ \\
\hline$l_{c}$ & total length & 23540 & $\mathrm{~mm}$ \\
\hline $2 l_{b}$ & wheelset base & 2.45 & $\mathrm{~m}$ \\
\hline $2 l_{w}$ & bogie base & 15.95 & $\mathrm{~m}$ \\
\hline$k_{1}$ & primary suspension stiffness & 500 & $\mathrm{kN} \mathrm{m}^{-1}$ \\
\hline$k_{2}$ & secondary suspension stiffness & 8800 & $\mathrm{kN} \mathrm{m}^{-1}$ \\
\hline$c_{1}$ & primary suspension damping & 0.5 & $\mathrm{kN} \mathrm{s} \mathrm{m}^{-1}$ \\
\hline \multirow[t]{2}{*}{$c_{2}$} & secondary suspension damping & 41.5 & $\mathrm{kN} \mathrm{s} \mathrm{m}^{-1}$ \\
\hline & Other simulation parameters & & \\
\hline$d t$ & time step & $6 \cdot 10^{-5}$ & $\mathrm{~s}$ \\
\hline$K_{h}$ & Hertz contact coefficient ${ }^{b}$ & $0.87 \cdot 10^{11}$ & $\mathrm{~N} \mathrm{~m}^{-3 / 2}$ \\
\hline$C_{h}$ & contact damping coefficient & $3 \cdot 10^{5}$ & $\mathrm{Ns} \mathrm{m}^{-1}$ \\
\hline$L_{s}$ & simulation line length $^{a}$ & 64.45 & $\mathrm{~m}$ \\
\hline$n$ & number of pad elements & 7 & \\
\hline$d$ & number of beam elements between sleepers & 9 & \\
\hline$N$ & number of defects functions & 200 & \\
\hline$\omega_{u}$ & upper pulsation & 1560 & $\operatorname{rads}^{-1}$ \\
\hline$\omega_{l}$ & lower pulsation & 12 & $\operatorname{rads}^{-1}$ \\
\hline$I_{l g}$ & line grade index & 1 & \\
\hline$V$ & train velocity & 90 & $\mathrm{~km} \mathrm{~h}^{-1}$ \\
\hline
\end{tabular}

${ }^{a}$ parameters extracted from [13]. 
Table 2: Model parameters adopted for the simulation in second railway line.

Case 2

\begin{tabular}{|c|c|c|c|}
\hline notation & parameter & value & unit \\
\hline & Model parameters of substructure & & \\
\hline$E$ & young modulus of rail ${ }^{a}$ & $2.07 \cdot 10^{11}$ & $\mathrm{Nm}^{-1}$ \\
\hline$I$ & inertial modulus of rail $^{b}$ & $2940 \cdot 10^{-8}$ & $\mathrm{~m}^{4}$ \\
\hline$A$ & section area of rail ${ }^{b}$ & $77.70 \cdot 10^{-4}$ & $\mathrm{~m}^{2}$ \\
\hline$\chi$ & Timoshenko shear coefficient ${ }^{b}$ & 0.34 & \\
\hline$m_{r}$ & railway mass ${ }^{a}$ (per unit length) & 60 & $\mathrm{~kg} \mathrm{~m}^{-1}$ \\
\hline$M_{s}$ & sleeper mass ${ }^{b}$ & 270 & $k g$ \\
\hline$M_{b}$ & ballast mass ${ }^{b}$ & 480 & $k g$ \\
\hline$k_{p}$ & pad stiffness ${ }^{a}$ & $57.65 \cdot 10^{6}$ & $\mathrm{Nm}^{-1}$ \\
\hline$c_{p}$ & pad damping ${ }^{a}$ & $33.65 \cdot 10^{3}$ & $\mathrm{Nsm}^{-1}$ \\
\hline$k_{b}$ & ballast stiffness ${ }^{c}$ & $29.06 \cdot 10^{6}$ & $\mathrm{Nm}^{-1}$ \\
\hline$c_{b}$ & ballast damping & $8.30 \cdot 10^{3}$ & $\mathrm{Nsm}^{-1}$ \\
\hline$k_{w}$ & horizontal stiffness ${ }^{c}$ & $7.84 \cdot 10^{6}$ & $\mathrm{Nm}^{-1}$ \\
\hline$c_{w}$ & horizontal damping ${ }^{c}$ & $2.49 \cdot 10^{3}$ & $\mathrm{~N} \mathrm{~s} \mathrm{~m}^{-1}$ \\
\hline$k_{f}$ & subgrade stiffness ${ }^{c}$ & $76.80 \cdot 10^{6}$ & $\mathrm{Nm}^{-1}$ \\
\hline$c_{f}$ & subgrade damping & $64.6 \cdot 10^{3}$ & $\mathrm{Nsm}^{-1}$ \\
\hline$l_{s l}$ & sleeper base $^{a}$ & 68.5 & $\mathrm{~cm}$ \\
\hline \multirow[t]{2}{*}{$L_{s}$} & effective length of rail support area ${ }^{b}$ & 16.4 & $\mathrm{~cm}$ \\
\hline & Model parameters of the train & & \\
\hline $2 M_{c}$ & car body mass $^{d}$ & 72000 & $\mathrm{~kg}$ \\
\hline$M_{b}$ & bogie mass ${ }^{b}$ & 3600 & $\mathrm{~kg}$ \\
\hline $2 M_{w}$ & wheelset mass ${ }^{b}$ & 1900 & $\mathrm{~kg}$ \\
\hline $2 l_{b}$ & wheelset base ${ }^{b}$ & 1.675 & $\mathrm{~m}$ \\
\hline $2 l_{w}$ & bogie base ${ }^{b}$ & 10.36 & $\mathrm{~m}$ \\
\hline$k_{1}$ & primary suspension stiffness $^{b}$ & 6500 & $\mathrm{kN} \mathrm{m}^{-1}$ \\
\hline$k_{2}$ & secondary suspension stiffness ${ }^{b}$ & 2555 & $\mathrm{kN} \mathrm{m}^{-1}$ \\
\hline$c_{1}$ & primary suspension damping ${ }^{b}$ & 10 & $\mathrm{kN} \mathrm{s} \mathrm{m}^{-1}$ \\
\hline$c_{2}$ & secondary suspension damping ${ }^{b}$ & 30 & $\mathrm{kN} \mathrm{s} \mathrm{m}^{-1}$ \\
\hline \multirow[t]{2}{*}{$r_{w}$} & wheel radius ${ }^{a}$ & 0.475 & $\mathrm{~m}$ \\
\hline & Other simulation parameters & & \\
\hline$d t$ & time step & $5.14 \cdot 10^{-5}$ & $\mathrm{~s}$ \\
\hline$K_{h}$ & Hertz contact coefficient ${ }^{b}$ & $0.87 \cdot 10^{11}$ & $\mathrm{~N} \mathrm{~m}^{-3 / 2}$ \\
\hline$n$ & number of pad elements & 7 & \\
\hline$d$ & number of beam elements between sleepers & 9 & \\
\hline$N$ & number of defects functions & 2500 & \\
\hline$\omega_{u}$ & upper pulsation & 555 & $\operatorname{rad~s}^{-1}$ \\
\hline$\omega_{l}$ & lower pulsation & 61 & $\operatorname{rad~s}^{-1}$ \\
\hline$I_{l g}$ & line grade index & 6 & \\
\hline$V$ & train velocity & 70 & $\mathrm{~km} \mathrm{~h}^{-1}$ \\
\hline
\end{tabular}

${ }^{a}$ Values extracted from [25]

${ }^{b}$ Values extracted form [5]

${ }^{c}$ Calculated Values 
Table 3: Model parameters adopted for evaluation of railway receptance.

\begin{tabular}{|c|c|c|c|}
\hline notation & parameter & value & unit \\
\hline & Model parameters of substructure & & \\
\hline$E$ & young modulus of rail & $2.07 \cdot 10^{11}$ & $\mathrm{Nm}^{-1}$ \\
\hline$I$ & inertial modulus of rail $^{a}$ & $2348 \cdot 10^{-8}$ & $\mathrm{~m}^{4}$ \\
\hline$A$ & section area of rail & $71.7 \cdot 10^{-4}$ & $\mathrm{~m}^{2}$ \\
\hline$\chi$ & Timoshenko shear coefficient $^{a}$ & 0.34 & \\
\hline$m_{r}$ & railway mass ${ }^{a}$ (per unit length) & 56 & $\mathrm{~kg} \mathrm{~m}^{-1}$ \\
\hline$M_{s}$ & sleeper mass ${ }^{a}$ & 220 & $\mathrm{~kg}$ \\
\hline$k_{p}$ & pad stiffness $^{a}$ & $280 \cdot 10^{6}$ & $\mathrm{Nm}^{-1}$ \\
\hline$c_{p}$ & pad damping ${ }^{b}$ & $35 \cdot 10^{3}$ & $\mathrm{Ns} \mathrm{m}^{-1}$ \\
\hline$k_{b}$ & ballast stiffness ${ }^{b}$ & $160 \cdot 10^{6}$ & $\mathrm{Nm}^{-1}$ \\
\hline$c_{b}$ & ballast damping ${ }^{b}$ & $90 \cdot 10^{3}$ & $\mathrm{Ns} \mathrm{m}^{-1}$ \\
\hline \multirow[t]{2}{*}{$l_{s l}$} & sleeper base ${ }^{a}$ & 69.8 & $\mathrm{~cm}$ \\
\hline & Other simulation parameters & & \\
\hline$n_{m s}$ & number of sleepers (midspan excitation) & 99 & \\
\hline$n_{o s}$ & number of sleepers (on-sleeper excitation) & 100 & \\
\hline$d t$ & time step & $3.37 \cdot 10^{-5}$ & s \\
\hline$n$ & number of pad elements & 8 & \\
\hline$d$ & number of beam elements between sleepers & 10 & \\
\hline
\end{tabular}

${ }^{a}$ Values extracted form [24]

${ }^{b}$ estimated Values 